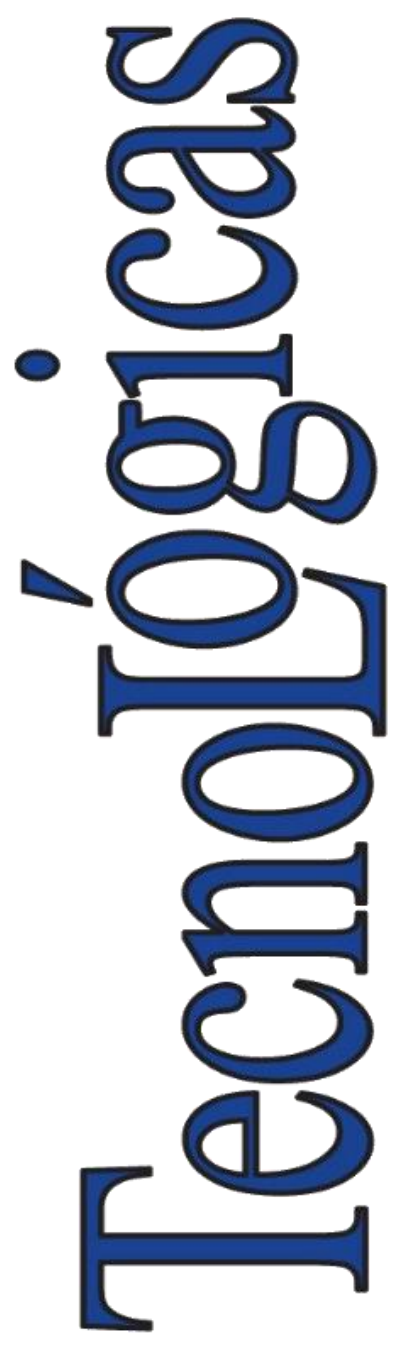

ISSN-p: 0123-7799 ISSN-e: $2256-5337$

Vol. 24, nro. 52, e2038, 2021

Recibido: 10 junio 2021 Aceptado: 11 noviembre 2021 Disponible: 01 diciembre 2021

CInstituto Tecnológico Metropolitano Este trabajo está licenciado bajo una Licencia Internacional Creative Commons Atribución (CC BY-NC-SA)

\section{Evaluación técnica del potencial cementante de arcillas provenientes de los residuos de la construcción y la demolición}

\section{Technical Evaluation of the Cementing Potential of Clays Obtained from Construction and Demolition Waste}

\author{
(D) Carlos Alberto Mejía-Barrera ${ }^{1}$; \\ (iD) Luis Javier Sierra-Arango²; \\ (iD) \\ Sergio Andrés Arboleda-López ${ }^{3}$; \\ (iD Ubany de Jesús Zuluaga-de los Ríos ${ }^{4}$

\begin{abstract}
${ }^{1}$ Universidad de San Buenaventura, Medellín-Colombia, carlos.mejia@usbmed.edu.co 2 Universidad de San Buenaventura, Medellín-Colombia, luis.sierra@usbmed.edu.co ${ }^{3}$ Institución Universitaria Colegio Mayor de Antioquia, Medellín-Colombia, sergio.arboleda@colmayor.edu.co ${ }_{4}^{4}$ Institución Universitaria Colegio Mayor de Antioquia, Medellín-Colombia, ubany.zuluaga@colmayor.edu.co
\end{abstract}

Cómo citar / How to cite

C. A. Mejía-Barrera; L. J. Sierra-Arango; S. A. Arboleda-López; U. de J. Zuluaga-de los Ríos, "Evaluación técnica del potencial cementante de arcillas provenientes de los residuos de la construcción y la demolición", TecnoLógicas, vol. 24, nro. 52, e2038, 2021.

https://doi.org/10.22430/22565337.2038 


\section{Resumen}

Esta investigación tiene como objetivo evaluar técnicamente el potencial cementante de arcillas provenientes de residuos de construcción y demolición (RCD), de ladrillo cerámico, baldosa cerámica y aparatos sanitarios en relación con el metacaolín, sustituyendo parcialmente el cemento Pórtland por cada uno de los materiales provenientes de los RCD. Inicialmente se obtuvieron los RCD y se sometieron a trituración primaria y secundaria con el fin de reducir su tamaño; luego a una trituración más fina hasta obtener un polvo con granulometría similar al del cemento tipo Pórtland. En la preparación de la matriz cementante, el cemento se sustituyó gradualmente por las arcillas provenientes de los RCD y del metacaolín, hasta encontrar mezclas con mejor desempeño mecánico al esfuerzo de compresión, lo anterior de acuerdo con la norma técnica colombiana NTC 220; posteriormente se le adicionó arena normalizada con el fin de preparar cilindros de concreto. Por último, utilizando las sustituciones parciales de arcillas por cemento Pórtland como material cementante, estas fueron sometidas a ensayos de petrografía y a fluorescencia y difracción de rayos X. En dichos ensayos se encontraron sustancias químicas similares, como portlandita y calcita que pueden representar, una vez sea posible identificar las fases cementantes de los materiales utilizados, un potencial agente cementante de las arcillas de baldosa cerámica y aparatos sanitarios provenientes de los RCD. Finalmente se pudo establecer que las arcillas provenientes de los RCD pueden ser útiles como relleno para mejorar las propiedades mecánicas del concreto o como agregados en morteros, revoques o enlucidos.

\section{Palabras clave}

Medio ambiente, recursos no renovables, cementos, reciclado de residuos, explotación excesiva, residuos de la construcción y la demolición.

\section{Abstract}

This paper aims to technically evaluate the cementing potential of clays obtained from Construction and Demolition Waste (CDW), as well as from ceramic brick, ceramic tile, and sanitary ware waste in terms of metakaolin, by partially replacing Portland cement with each of the materials recovered from CDW. First, CDWs were collected and subjected to primary and secondary crushing to reduce their size. Then, they were finely milled until a powder with a granulometry similar to that of Portland cement was obtained. When preparing the cementitious matrix, the cement was gradually replaced with the clays derived from CDW and metakaolin until mixtures with a better compression strength performance were obtained in accordance with Colombian Technical Standard 220 (abbreviated NTC 220 in Spanish). Afterward, standardized sand was added to the mixture to make concrete cylinders. Finally, the partial substitutions of Portland cement by clays as cementitious material were subjected to petrography tests and X-ray fluorescence and diffraction. During these tests, similar chemical substances, such as portlandite and calcite, were observed. These substances could become a potential cementing agent in ceramic tile and sanitary ware clays from CDW once the cementing phases of the materials used are identified. The results suggest that clays from CDW can be employed as fillers to improve the mechanical properties of concrete or as aggregates in mortars or plasters.

\section{Keywords}

Environment, nonrenewable resources, cements, waste recycling, excessive exploitation, construction and demolition waste. 


\section{INTRODUCCIÓN}

En la sociedad contemporánea el ser humano no desea perder los privilegios en su manera de vivir, de relacionarse y de transformar su entorno; en tanto, la raza humana no va a renunciar a su modo de vida; sin embargo, el mundo siempre estará en constante cambio y construcción, y esto, como tal, acarrea impactos, ya sean positivos o negativos, por lo que se debe evitar afectar lo menos posible dichos entornos. Es precisamente en este punto donde se encuentra la brecha de discusión del presente trabajo.

Los impactos generados por la extracción y la transformación de productos asociados a la construcción pueden ser: cambios en el paisaje, ruido, alteraciones de flujos de agua, remoción de la capa vegetal, erosión del suelo, aumento de partículas suspendidas en el aire, entre otros, esto sin tener en cuenta tres hechos relacionados: el primero es la construcción misma, ya sea de la obra edilicia o de infraestructura; el segundo tiene que ver con el mantenimiento de la obra durante el periodo de su vida útil; y la tercera se encuentra ligada al fin de la vida útil de la edificación; es decir, una obra de construcción genera impactos antes de su construcción, durante su construcción, en el periodo de su vida útil y al final de esta.

El presente trabajo pretende evaluar tres tipos de arcillas cerámicas provenientes de los RCD para determinar técnicamente su potencial cementante. Para este ejercicio se evaluaron las arcillas provenientes de ladrillos cerámicos, baldosas cerámicas y aparatos sanitarios, contrastando estos con arcillas utilizadas en el campo industrial para mejorar la resistencia al esfuerzo a la compresión de los concretos como el metacaolín (Mk).

Estos productos fueron sustituyendo, de manera parcial, el cemento tipo Pórtland de uso general, en proporciones del $25 \%, 50 \%, 75 \%$ y $100 \%$ en la elaboración de una matriz cementante que posteriormente se sometió a esfuerzos de compresión, eligiendo los de mayores desempeños y que se ajustaran a la NTC 220 y a la NSR 10 - Título D.

Una vez se definieron las proporciones de la matriz cementante con las sustituciones de arcillas por cemento tipo Pórtland, se realizaron especímenes que contenían solo la matriz cementante y especímenes con agregado fino con alto contenido de cuarzo; estos especímenes fueron sometidos a diferentes ensayos de fluorescencias y difracción de rayos $\mathrm{X}$, además de petrografía, esto con el fin de determinar los componentes químicos y sus compuestos que se encuentran conformando la matriz cementicia y poder inferir si existe o no potencial cementante en las arcillas provenientes de los RCD.

\subsection{Revisión literaria}

El concreto, en la industria de la construcción, es sumamente importante, sobre todo en el contexto actual, donde los materiales necesarios para su confección se encuentran cercanos a lugares donde se desarrollan actividades edilicias. "El concreto se ha consolidado como el material de construcción más utilizado en el mundo. Ha sido considerado también, como la segunda sustancia después del agua más usada en la tierra" [1].

Existe una relación directa desde el punto de vista sistémico entre las canteras a cielo abierto, de donde se extraen materiales pétreos para la confección de concreto, y las comunidades cercanas a las minas, trayendo a estos últimos impactos negativos. "Se verificó de manera indirecta la presencia de PST que, accionadas por el viento, con su magnitud y dirección, desgastan aceleradamente las fachadas que se encuentran orientadas hacia el norte, es decir en dirección a la cantera" [2] Lo anterior, desde el punto de vista mecánico; ahora bien, si hablamos desde el punto de vista medioambiental, los recursos minerales no renovables extraídos como materia prima para el sector de la construcción son inmensamente altos en nuestro medio, estas acciones antrópicas no solamente generan cambios en el paisaje, 
sino también en la bioma donde se encuentra ubicada la extracción de material. "Los usos del suelo de la cantera, si no fuera empleado como explotación, obedece a bosques (plantado) y a pastos/tierra de montaña que generan 10 servicios ambientales, los cuales son: regulación de gases, regulación del agua, control de erosión, polinización, control biológico, producción de alimentos, abastecimiento de agua, formación de suelo, materias primas y regulación del clima" [2]. Por lo tanto, se puede decir que, si bien existe un impacto sobre el territorio en el ejercicio constructivo, la consecución de materias primas para este también tiene consecuencias sobre el ecosistema; es decir, existe un triple impacto en el ejercicio de la construcción: el primero asociado a la extracción de materias primas; el segundo, en la transformación de materias primas; y el tercero, asociado a la labor propia de la construcción.

La confección de concreto supone una mezcla heterogénea de materiales. "El concreto hidráulico u hormigón, es una mezcla homogénea de cemento, agua, arena y grava y en algunos casos de aditivos" [3] que, al mezclarse, se mantienen unidas a través de una matriz. Este material pasa por varios estados, desde el plástico hasta el sólido. En el estado plástico se le puede dar forma al concreto hasta que este fragüe y se endurezca.

El cemento de uso frecuente en Colombia para la producción de concreto es el cemento tipo Pórtland gris; de acuerdo con el informe Construcción en Cifras de la Cámara Colombiana de la Construcción, la producción de cemento Pórtland en Colombia asciende a más de 10 millones de toneladas al año, [4]. El informe, además, indica que entre enero y agosto del 2021 se han producido 8864312 toneladas de cemento gris tipo Pórtland, de los cuales se despacharon, en ese mismo periodo del año, 8425280 de toneladas a los distribuidores al por mayor, al detal y a los constructores en todo el país. "El cemento Portland ordinario (OPC), es uno de los materiales para la construcción más empleados en la producción de concreto, debido fundamentalmente, a las excelentes propiedades mecánicas que presenta en estado endurecido" [5].

Para la producción del cemento, el material principal es la roca caliza, la cual es extraída en canteras, ya sea por arranque del material con maquinaria pesada o realizando voladuras con pólvora; después de esto, la roca es cargada y transportada por camiones de gran porte hacia la planta de trituración primaria. En este punto las rocas de caliza son trituradas, reduciendo su tamaño de dimensiones mayores de $700 \mathrm{~mm}$ hasta tamaños inferiores de $60 \mathrm{~mm}$; después, una trituración secundaria reduce nuevamente su tamaño, pasando de partículas con diámetros de hasta $60 \mathrm{~mm}$, a diámetros entre 0,02 $\mathrm{mm}$ y 0,006 $\mathrm{mm}$; luego se inicia con la preparación de un crudo a partir de una serie de materias primas seleccionadas previamente. Entre ellas se cuenta con calizas margas o arcillas. Éstas van acompañadas a otros modificadores de módulos como cenizas de peritas y arenas, entre otros. Todo esto constituye el crudo de cemento el cual luego es introducido en un precalcinador de manera continua en un horno cilíndrico rotatorio, allí puede permanecer entre 20 y 30 minutos a temperaturas que pueden variar entre $\operatorname{los} 850{ }^{\circ} \mathrm{C}$ y $1500{ }^{\circ} \mathrm{C}$. Como resultado se forma el mineral determinado como clínker. Luego de que este se enfría, se muele con un regulador de fraguado, para lo cual, generalmente, se usa yeso y otros materiales calizos con adicciones, dando como resultado final el cemento [6].

Para la preparación del cemento se requiere un gran gasto energético, traducido en el funcionamiento de la planta, transporte de material, encendido de hornos, entre otros, que, sumados, se convierten en impactos para el medio ambiente, según lo cita [7]. "Se estima que a nivel mundial las emisiones promedio de carbono en la producción de cemento son de $0,81 \mathrm{~kg}$ de $\mathrm{CO}_{2}$ por kilogramo de cemento. Según Hendriks et al [7], un poco más del $50 \%$ de las emisiones se deben al proceso de calcinación de la materia prima que por su naturaleza calcárea poseen altos contenidos de carbonatos, los cuales al ser sometidos a altas temperaturas son eliminados en forma gaseosa (dióxido de carbono)". Esas grandes masas de 
$\mathrm{CO}_{2}$ en el medio ambiente contribuyen al daño de la capa de ozono y al efecto invernadero; la extracción de caliza en zonas con protección de suelos contribuye a la aceleración de la erosión por acciones antropogénicas, afecta la bioma, el control de las aguas de escorrentía superficial, la producción de oxígeno y agua, y al efecto de isla de calor, aumentando la temperatura promedio de la zona a la cual se expone la roca a los rayos directos del sol al retirar del suelo de la zona la capa vegetal; es decir, la producción de cemento no solo es un asunto de minería a cielo abierto sino de múltiples variables que van desde los aspectos técnicos hasta los aspectos de índole social.

El cemento tipo Pórtland, materia prima para el sector de la construcción, puede emanar al medio ambiente el equivalente al $80 \%$ de $\mathrm{CO}_{2}$ de su peso en la producción; esto genera cambios locales en los servicios ambientales que presta el ecosistema afectado en la zona de explotación de roca; su producción, afecta a comunidades cercanas a la mina a cielo abierto y genera impactos sobre el paisaje. Por otro lado, se observa una gran cantidad de residuos derivados del sector de la construcción en las ciudades, como es el caso del Área Metropolitana del Valle de Aburrá (AMVA), "la gestión de residuos en el área metropolitana se ha convertido en un problema complejo. Éstos llegan a escombreras (4600 t/día) y rellenos sanitarios legales (2400 t/día) bastante cuestionados, y a cursos de agua o zonas que no están acondicionadas para ello (3400 t/día). Desafortunadamente, en el área metropolitana sólo se recicla aproximadamente 1000 t/día" [8]. Gran parte de los residuos de construcción y demolición (RCD) están constituidos por materiales cerámicos. Entre el $7 \%$ y el $11 \%$ del total del volumen llega a las escombreras oficiales, donde se puede reconocer y cuantificar los materiales sometidos a quemas de alto horno que podrían sustituir de manera parcial la matriz cementante en la confección de concretos.

La utilización de materias primas, renovables y no renovables, por el sector de la construcción es alto, "se podría decir que el proceso constructivo consume una gran cantidad de materias primas como: arena, grava, arcilla, carbonato de calcio, agua, áridos, madera, hierro, asfalto, aluminio y combustible para los vehículos" [9] incluso, en el AMVA existen "1498 hectáreas (ha) comprometidas con minería" [10], las cuales no necesariamente se encuentran en explotación activa; sin embargo, los áridos para la confección de concreto, las arcillas para la elaboración de materiales cerámicos, entre otros, son abastecidos gracias a la gran cantidad y diversidad de materiales litológicos depositados a lo largo de las laderas que conforman el área metropolitana.

En el ámbito nacional se han realizado investigaciones en concretos adicionados con diferentes tipos de puzolanas, inclusive con limallas de acero con el fin de aumentar la resistencia al esfuerzo de compresión, donde se ha podido determinar que la adición de limalla de acero en la confección de concretos aumenta su esfuerzo a la compresión. De acuerdo con trabajo titulado "Estudio del comportamiento de la mezcla de agregados adicionados con el 3,5, 4,5 y 5,5 de limalla fina, para las mezclas de concreto" [11], el ingeniero Alejandro Salazar Jaramillo, profesor de la Universidad del Valle y director de la empresa Eco Ingeniería, quien se ha dedicado en años recientes al desarrollo y estudio de los diferentes tipos de concretos, sobre todo de aquellos que se encuentran expuestos a ambientes urbanos, asegura que se debe tener en cuenta la durabilidad del mismo en la línea del tiempo. De igual forma, en su estudio del 2004 titulado "Estudio de la durabilidad de concretos adicionados con escoria siderúrgica, con diferentes formas de curado" se pudo demostrar que la manera en la que se cura el concreto adicionado también influye en la durabilidad de este, máxime cuando los ambientes urbanos se encuentran cada vez más deteriorados. Asimismo, la resistencia a la compresión aumenta en la medida que se le adicionan a la mezcla mayores cantidades de escoria siderúrgica. También se determinó que la penetrabilidad de iones de cloruro en concretos 
adicionados con escorias siderúrgicas es menor que para un concreto tradicional y la importancia en los curados de los concretos, sobre todo cuando son adicionados.

Para concretos adicionados con $\mathrm{Mk}$, de acuerdo al estudio "Concreto adicionado con metacaolín: Comportamiento a carbonatación y cloruros" arrojaron una resistencia a la compresión un poco inferior, solo un $9 \%$; con respecto a los concretos tradicionales, al igual que la penetración por iones de cloruro, los adicionados con metacaolines presentaron menores penetraciones al cloruro, y en la penetración de la carbonatación se pudo estimar que en las primeras edades del concreto, existe un mayor avance en el frente de carbonatación en los concretos adicionados con Mk con respecto a los concretos tradicionales; sin embargo, a una edad de 240 días, el frente de carbonatación es similar en los concretos adicionados con Mk con respecto a los concretos sin adición [12].

Uno de los mayores problemas existentes con los concretos se debe a los espacios que se encuentran entre las moléculas y que quedan libres por diferentes razones. Una de ellas puede ser el tamaño del material cementante para ocupar estos intersticios, por ende, las cenizas de alto horno han dado muy buenos resultados debido que estas, al ser de menor tamaño, pueden ocupar estos espacios libres.

En el mundo se vienen considerando diferentes alternativas en el proceso de producción del cemento, de las cuales han tomado mayor importancia la eficiencia energética y el uso de materiales alternativos que reemplacen el uso de combustibles, los cuales siguen aumentado. Pero afirman Pounds T. M. (2009) y Schneider M. et al. (2011), citados por [12], que, en cuanto al remplazo de materiales alternativos, la cantidad de clínker para producción de cemento continúa siendo un asunto en el que hay mucho por trabajar.

Una muestra se lee en el documento de Construcción y tecnología (1992), citado por [13], que define que, debido a los crecientes efectos que esto genera en materia de contaminación ambiental con respecto a la cantidad de materiales y procesos que conlleva, se analizaron cuáles eran las emisiones producidas durante el proceso de fabricación del clínker en el horno para producir cemento Pórtland, y el 50 \% provenía de la combustión y el otro 50 \% de la descarbonización caliza.

La elaboración de concretos con RCD se realiza actualmente reemplazando parcial o totalmente los áridos finos y los gruesos de origen natural por aquellos que provienen de los RCD; por su parte, la elaboración de concretos con arcillas expandidas incorporadas al concreto se realiza a manera de agregado, no de cementante. Estos tipos de ensayos han arrojado resultados muy alentadores: "Se encontraron en los concretos estudiados, resistencias a la compresión a los 28 días de 29 y $37 \mathrm{MPa}$ para relaciones a/mc de 0,77 y 0,72, respectivamente; las cuales son muy superiores a la mínima requerida por la normativa ACI 213R-03 (17,5 MPa) para clasificarlo como hormigón estructural. Así mismo, estas resistencias alcanzadas superan el mínimo valor de resistencia a la compresión $(21 \mathrm{MPa})$ especificado por la NSR-10, para ser utilizado en sistemas sismo-resistentes." [14], pero como se puede observar estas arcillas son utilizadas a manera de agregado.

De acuerdo con el informe Effects of Coarse Aggregate Clay-Coatings on Concrete Performance, elaborado por la Universidad de Wisconsin-Madison (Estados Unidos), que ha investigado acerca de las propiedades técnicas en la utilización de materiales cerámicos provenientes de los RCD en la fabricación de losas de pavimentos con hormigón, donde se arrojan resultados de desprendimientos en las esquinas y fisuras a lo largo de las losas, sobre todo en los pavimentos utilizados para aeropuertos, [15], y en el cual nuevamente la viabilidad técnica se centra en la utilización de los residuos como agregado en la confección de concretos, en este caso específico para vías y transporte, "Estos estudios han revelado que la presencia de algún tipo de arcillas en la mezcla de cemento puede producir una disminución en la resistencia y un aumento en la contracción del concreto... para la fabricación de una mezcla 
de cemento viable relacionada con la superficie específica en función del área de las arcillas presentes en el cemento. Señaló que un reemplazo del $3 \%$ de arena disminuyó la resistencia a la compresión en casi un 40 \% y se duplicó la cantidad de contracción del concreto" [14]. Lo que no queda claro es la proveniencia de las arcillas utilizadas para la elaboración de los concretos, lo que puede suponer una utilización de arcillas que no necesariamente estuvieran asociadas a altos hornos donde estas cambiaran sus propiedades fisicoquímicas a través de la sinterización.

Dado que en efecto los RCD provenientes de los cerámicos fueron inicialmente arcillas en estado natural, para poder adquirir su resistencia fueron sometidos a procesos de sinterización, mejorando las propiedades fisicomecánicas del material mismo, tal cual sucede con las baldosas cerámicas, ladrillos cerámicos y otros productos utilizados comúnmente en la construcción. La caolinita $\mathrm{Al} 2 \mathrm{Si} 2 \mathrm{O} 5(\mathrm{OH}) 4$, o disilicato de alúmina hidratado, es el término más común para las arcillas de caolín. "El metacaolín es un material cementante suplementario, dado que es un aluminosilicato activado térmicamente que se produce al calcinar el caolín a temperaturas alrededor de $500 \mathrm{i}^{1} / 2{ }^{\circ} \mathrm{C}$ y $600 \mathrm{i}^{1} / 2{ }^{\circ} \mathrm{C}$, a esta temperatura se produce una transformación de su estructura cristalina” [16].

Entre $100{ }^{\circ} \mathrm{C}$ y $200{ }^{\circ} \mathrm{C}$, los minerales arcillosos pierden la mayor parte de su agua adsorbida. La temperatura a la que la caolinita pierde agua por deshidroxilación está en el rango de $500{ }^{\circ} \mathrm{C}$ a $800{ }^{\circ} \mathrm{C}$. Esta activación térmica de un mineral también se conoce como calcinación. Más allá de la temperatura de deshidroxilación, la caolinita retiene un orden bidimensional en la estructura cristalina y el producto se denomina metacaolín. La clave en la producción de metacaolín, para su uso como material de cementación suplementario o puzolana, es lograr la deshidroxilación más cercana posible sin sobrecalentamiento [17].

Dado que el Mk proviene inicialmente de arcillas, se parte de la intencionalidad para indagar la posible utilización de RCD cerámicos como probable material sustituyente parcial del cemento, ya que estos materiales son arcillas derivadas de altos hornos, que primero fueron tratados a partir de la calcinación para adquirir resistencia mecánica, tales como baldosas cerámicas, ladrillos de arcilla cocido y aparatos sanitarios. Esta situación conlleva a una nueva discusión frente a la labor en el ejercicio de la construcción y el diseño, y en la utilización de materiales cerámicos de altos hornos como posible material cementante, donde se podrían demandar menos recursos no renovables en la elaboración de cemento tipo Pórtland y sustituirlos por recursos que en el ciclo de vida ya van de salida, de tal manera que estos materiales tengan una revalorización y puedan incorporarse otra vez a los ciclos de vida de un nuevo material, aumentando entonces su horizonte de vida útil en los entornos.

\section{METODOLOGÍA}

El ejercicio aborda un análisis cuantitativo en cuanto al desempeño, esfuerzo y compresión de diferentes mezclas, sustituyendo, de manera parcial, el cemento tipo Pórtland por el polvo de material cerámico proveniente de los RCD. En este caso se analizaron muestras de ladrillo cerámico, baldosa cerámica y aparatos sanitarios; posteriormente se hizo un análisis cualitativo a partir de ensayos de análisis químico cuantitativo y petrográfico, así como de difracción de rayos $\mathrm{X}$.

Inicialmente se definieron los materiales provenientes de los RCD a analizar, estos son: ladrillo cerámico, baldosa cerámica y aparatos sanitarios, posteriormente se pasaron por procesos de trituración primaria (trituradora de quijada o mandíbula) y trituración secundaria (trituradora de cono) (observar Figuras 1, 2 y 3) con el fin de reducir el tamaño de 
sus partículas. Finalmente se pasa a la trituradora de bolas (o molino de bolas) con el fin de pulverizar las muestras y obtener granulometrías inferiores a $50 \mu$.

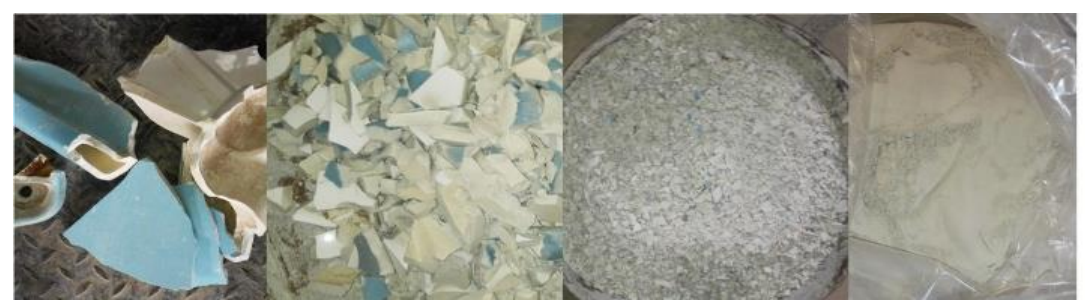

Figura 1. Proceso de trituración de aparatos sanitarios Fuente: elaboración propia.

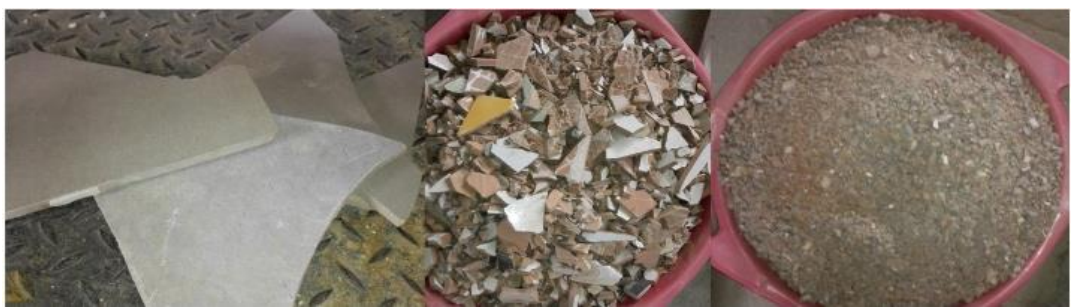

Figura 2. Proceso de trituración de baldosa cerámica Fuente: elaboración propia.

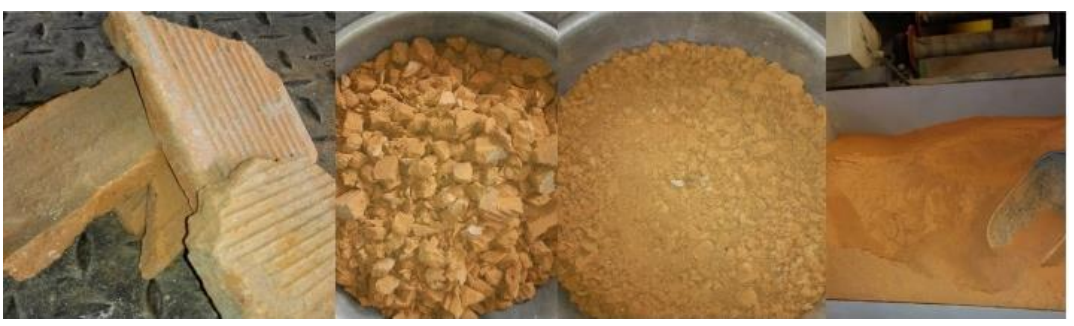

Figura 3. Proceso de trituración de ladrillo cerámico Fuente: elaboración propia.

Una vez el material ha pasado por el último proceso de trituración, se tamiza con mallas \#200 (Figura 4), es decir, partículas inferiores a $74 \mu$, con el fin de aproximar el tamaño de partícula a las del cemento tipo Pórtland.

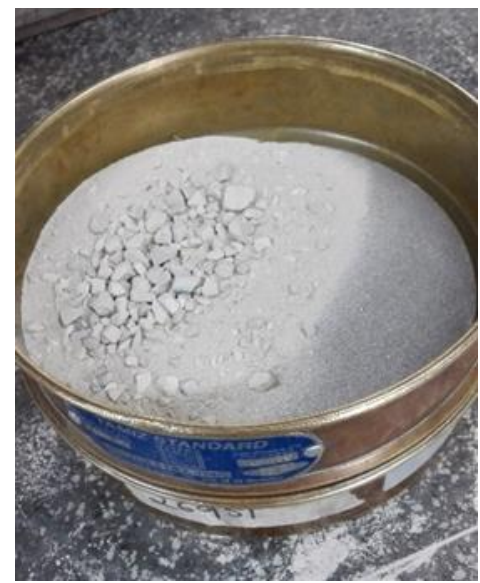

Figura 4. Proceso de tamizaje de los cerámicos provenientes de los RCD Fuente: elaboración propia. 
Posteriormente se realizaron los diseños de mezclas sustituyendo de manera parcial el cemento tipo Pórtland por los cerámicos de ladrillo, baldosa y aparatos sanitarios provenientes de los RCD y, de igual manera, con el Mk como material cementante, de manera que la sumatoria del cemento tipo Pórtland y el sustituyente sea el 100 \% (ver Tabla 1).

Tabla 1. Diseños de mezcla de material cementante. Fuente: elaboración propia.

\begin{tabular}{ccccccc} 
& \multicolumn{5}{c}{ Material Cementante \% } \\
\hline \multirow{2}{*}{ Muestra } & Nomenclatura & $\begin{array}{c}\text { Cemento } \\
\text { Tipo } \\
\text { Pórtland }\end{array}$ & $\begin{array}{c}\text { Polvo de } \\
\text { ladrillo } \\
\text { cerámico }\end{array}$ & $\begin{array}{c}\text { Polvo de } \\
\text { baldosa } \\
\text { cerámica }\end{array}$ & $\begin{array}{c}\text { Polvo de } \\
\text { aparatos } \\
\text { sanitarios }\end{array}$ & Metacaolín \\
\hline 1 & & 100 & 0 & 0 & 0 & 0 \\
2 & & 25 & 75 & 0 & 0 & 0 \\
3 & $\mathrm{C}+\mathrm{L}$ & 50 & 50 & 0 & 0 & 0 \\
4 & & 75 & 25 & 0 & 0 & 0 \\
5 & & 25 & 0 & 75 & 0 & 0 \\
6 & $\mathrm{C}+\mathrm{B}$ & 50 & 0 & 50 & 0 & 0 \\
7 & & 75 & 0 & 25 & 0 & 0 \\
8 & & 25 & 0 & 0 & 75 & 0 \\
9 & $\mathrm{C}+\mathrm{AS}$ & 50 & 0 & 0 & 50 & 0 \\
10 & & 75 & 0 & 0 & 25 & 0 \\
11 & & 0 & 0 & 0 & 0 & 100 \\
12 & & 25 & 0 & 0 & 0 & 75 \\
13 & & 50 & 0 & 0 & 0 & 50 \\
14 & & 75 & 0 & 0 & 0 & 25 \\
\hline
\end{tabular}

Con esta distribución de mezcla sustituyente por cemento tipo Pórtland, se realizan cubos de $50 \mathrm{~mm}$ de lado, tres de cada muestra, y se dejan en la cámara de curado por un tiempo de 28 días para luego ser sometidos al esfuerzo de compresión y determinar su resistencia mecánica a este esfuerzo tal cual lo indica la NTC 220, ensayo que sirve para determinar la calidad del cemento hidráulico al esfuerzo de compresión (ver Tabla 1 y Figuras 5, 6, 7, 8 y 9). Los resultados (ver Figura 5) serán los blancos o especímenes para comparar.

Como se pudo ver en la Tabla 1 y en las Figuras 5, 6, 7, 8 y 9, los comportamientos al esfuerzo de compresión varían según se va sustituyendo el cemento tipo Pórtland por el material cerámico o el Mk, donde en algunos casos las resistencias a este tipo de esfuerzo son tan bajas que se descarta la continuidad de su análisis.

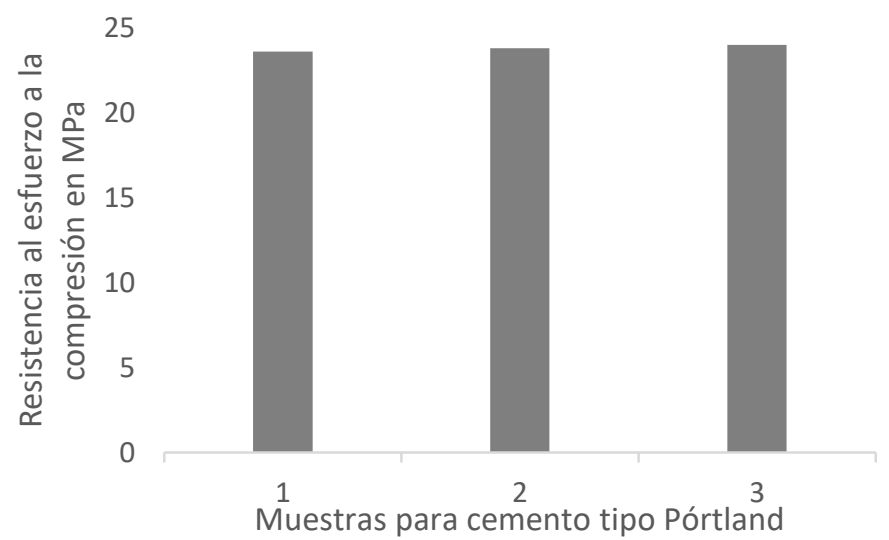

Figura 5. Resultado al esfuerzo a la compresión para muestras de 100\% cemento Pórtland Fuente: elaboración propia. 


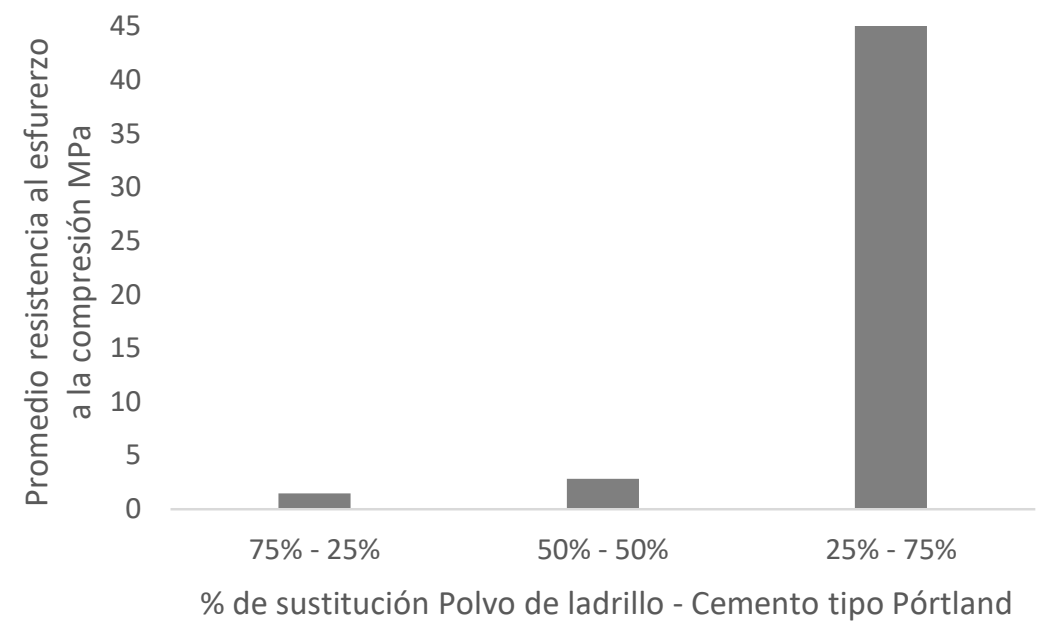

Figura 6. Resultados al esfuerzo a la compresión para muestras con sustitución de cemento Pórtland por polvo de ladrillo cerámico. Fuente: elaboración propia.

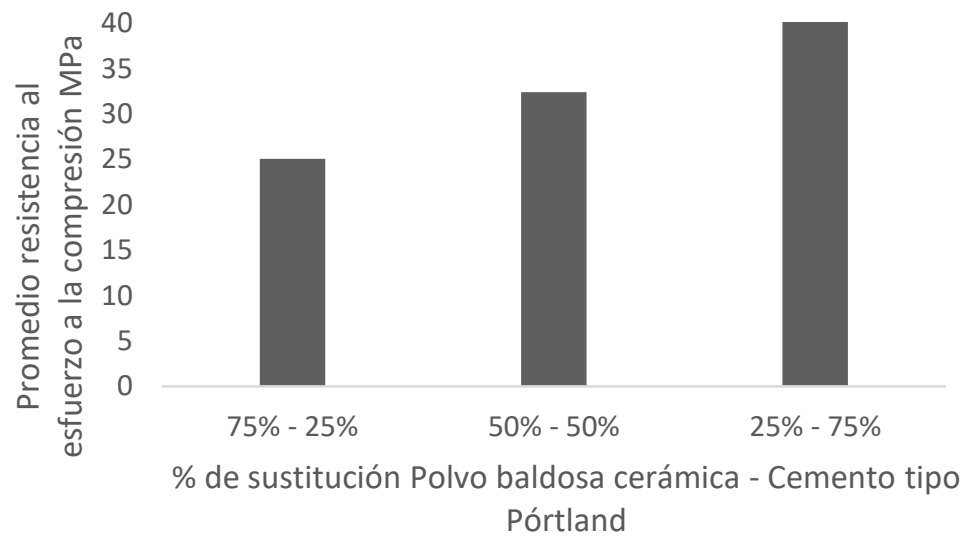

Figura 7. Resultados al esfuerzo a la compresión para muestras con sustitución de cemento Pórtland por polvo de baldosa cerámico. Fuente: elaboración propia.

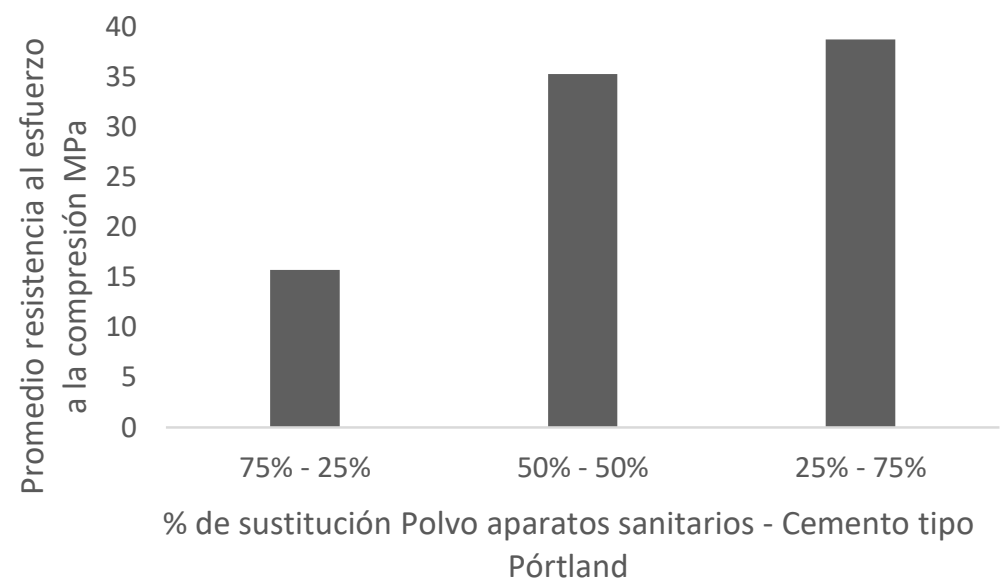

Figura 8. Resultados al esfuerzo a la compresión para muestras con sustitución de cemento Pórtland por polvo de aparatos sanitarios. Fuente: elaboración propia. 
Adicionalmente, se realizaron muestras con $\mathrm{Mk}$, continuando con las sustituciones planteadas anteriormente y poder lograr un análisis comparativo entre muestras y determinar la eficiencia en el comportamiento al esfuerzo a la compresión (ver Tabla 1 y Figura 9).

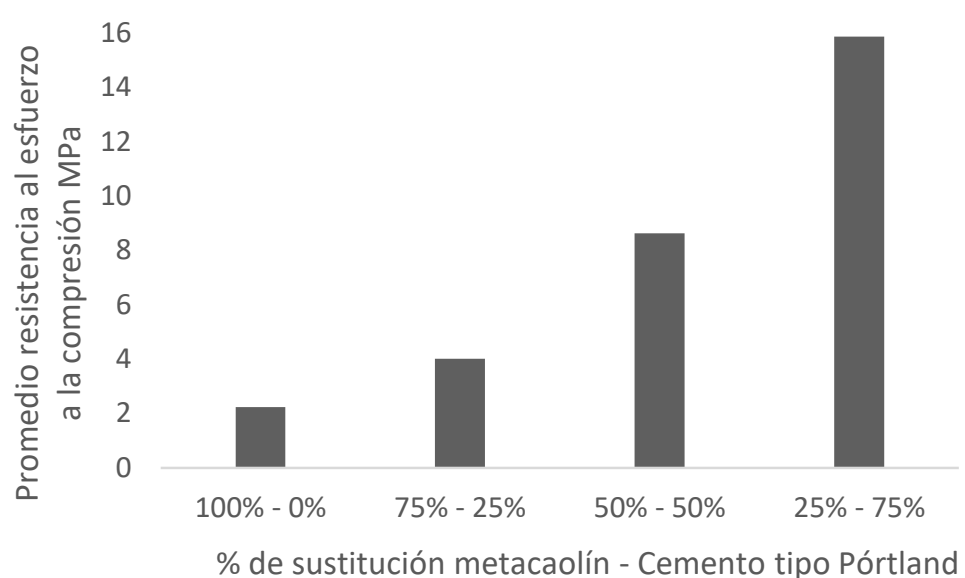

Figura 9. Resultados al esfuerzo a la compresión para muestras con sustitución de cemento Pórtland por Mk. Fuente: elaboración propia.

Por otro lado, se observó que las mezclas de Mk son menos pesadas que las que utilizan cemento tipo Pórtland o adiciones de material cerámico proveniente de los RCD; en tanto, se infirió que las mezclas adicionadas con $\mathrm{Mk}$ son menos densas que las adicionadas con material cerámico proveniente de RCD, e incluso que el cemento tipo Pórtland, lo que puede generar menor capacidad de resistencia al esfuerzo a la compresión.

Una vez se estableció la resistencia al esfuerzo a la compresión de los cubos de $50 \mathrm{~mm}$ de lado de cemento tipo Pórtland y sus diferentes sustituciones de material cerámico proveniente de los RCD como posible material cementante, se procedió a elegir las mezclas de mayor desempeño y que estuvieran dentro de los parámetros de resistencia según la NTC 220 (ver Tabla 2).

Tabla 2. Mezclas de material cementante. Fuente: elaboración propia.

\begin{tabular}{ccc}
\hline Muestra & Identificación & Ponderación \\
\hline 1 & Cemento $100 \%$ & Material cementante \\
2 & $50 \%$ Cemento $50 \%$ Aparato sanitario & Material cementante \\
3 & $50 \%$ Cemento $50 \%$ BALDOSA Cerámica & Material cementante \\
4 & $75 \%$ Cemento $25 \%$ Metacaolín & Material cementante \\
\hline
\end{tabular}

De acuerdo con el desempeño inicial de los cubos de $50 \mathrm{~mm}$ de lado frente al esfuerzo a la compresión, el cual establece el desempeño del material cementante, se descarta el polvo de arcilla proveniente de los RCD del ladrillo cerámico, debido a su bajo desempeño frente a esta prueba.

En la sustitución del 25 \% de arcillas de ladrillo cerámico y 75 \% de cemento tipo Pórtland, los valores fueron altos con respecto al ensayo de la resistencia mecánica de cementos 
hidráulicos de acuerdo a la NTC 220; sin embargo, al momento de realizar el ensayo con este diseño de mezcla y agregado fino (arena normalizada), los resultados no fueron los esperados y los especímenes elaborados no tuvieron el comportamiento deseado en términos de resistencia y durabilidad; por lo tanto, se identificó que el polvo de ladrillo cerámico podría ser utilizado como sustituyente parcial de agregados finos para uso en morteros de elementos no estructurales y no como potencial cementante.

Asumiendo la metodología empleada de análisis comparativo frente a mezclas de iguales proporciones, y teniendo en cuenta que el objetivo es determinar de alguna manera las propiedades cementicias de las arcillas provenientes de los RCD, se establece entonces la preparación de cilindros con material cementante y arena normalizada, que para el caso específico utilizó arena del municipio de Amagá (Antioquia) con alto contenido de cuarzo y se realizaron mezclas de diferentes proporciones como se muestra en la Tabla 3, con material cementante solo y con agregado, de la siguiente manera:

Tabla 3. Proporciones de mezclas para análisis. Fuente: elaboración propia.

\begin{tabular}{|c|c|c|c|c|c|}
\hline Muestra & Identificación & Ponderación & Componentes & $\begin{array}{l}\text { Proporción } \\
\text { en peso }(g)\end{array}$ & $\begin{array}{c}\% \text { de } \\
\text { material }\end{array}$ \\
\hline 1 & Cemento (C) & $\begin{array}{c}\text { Material } \\
\text { cementante }\end{array}$ & Cemento tipo Pórtland & 4000 & 100 \\
\hline \multirow[b]{2}{*}{2} & \multirow{2}{*}{$\begin{array}{l}100 \% \text { Cemento }+ \\
\text { arena }(\mathrm{C}+\mathrm{A})\end{array}$} & $\begin{array}{c}\text { Material } \\
\text { cementante }\end{array}$ & Cemento tipo Pórtland & 1000 & 20 \\
\hline & & Agregado & $\begin{array}{l}\text { Arena de Amagá (alto contenido } \\
\text { de cuarzo) }\end{array}$ & 4000 & 80 \\
\hline \multirow[b]{2}{*}{3} & \multirow{2}{*}{$\begin{array}{l}50 \% \text { Cemento } 50 \% \\
\text { aparato sanitario } \\
(\mathrm{C}+\mathrm{AS})\end{array}$} & \multirow{2}{*}{$\begin{array}{c}\text { Material } \\
\text { cementante }\end{array}$} & Cemento tipo Pórtland & 2000 & 50 \\
\hline & & & $\begin{array}{l}\text { Polvo de aparato sanitario } \\
\text { molido (pasa la malla \#200) }\end{array}$ & 2000 & 50 \\
\hline \multirow{3}{*}{4} & \multirow{3}{*}{$\begin{array}{l}50 \% \text { Cemento } 50 \% \\
\text { aparato sanitario + } \\
\text { arena }(\mathrm{C}+\mathrm{AS}+\mathrm{A})\end{array}$} & \multirow{2}{*}{$\begin{array}{c}\text { Material } \\
\text { cementante }\end{array}$} & Cemento tipo Pórtland & 500 & 10 \\
\hline & & & $\begin{array}{l}\text { Polvo de aparato sanitario } \\
\text { molido fino (pasa la malla \#200) }\end{array}$ & 500 & 10 \\
\hline & & Agregado & $\begin{array}{l}\text { Arena de Amagá (alto contenido } \\
\text { de cuarzo) }\end{array}$ & 4000 & 80 \\
\hline \multirow[b]{2}{*}{5} & \multirow{2}{*}{$\begin{array}{l}50 \% \text { Cemento } 50 \% \\
\text { baldosa cerámica } \\
(\mathrm{C}+\mathrm{B})\end{array}$} & \multirow{2}{*}{$\begin{array}{l}\text { Material } \\
\text { cementante }\end{array}$} & Cemento tipo pórtland & 2000 & 50 \\
\hline & & & $\begin{array}{l}\text { Polvo de baldosa cerámica } \\
\text { molida fina (pasa la malla \#200) }\end{array}$ & 2000 & 50 \\
\hline \multirow{3}{*}{6} & \multirow{3}{*}{$\begin{array}{l}50 \% \text { Cemento } 50 \% \\
\text { baldosa cerámica }+ \\
\text { arena }(\mathrm{C}+\mathrm{B}+\mathrm{A})\end{array}$} & \multirow{2}{*}{$\begin{array}{c}\text { Material } \\
\text { cementante }\end{array}$} & Cemento tipo Pórtland & 500 & 10 \\
\hline & & & $\begin{array}{l}\text { Polvo de baldosa cerámica } \\
\text { molida fina (pasa la malla \#200) }\end{array}$ & 500 & 10 \\
\hline & & Agregado & $\begin{array}{l}\text { Arena de Amagá (alto contenido } \\
\text { de cuarzo) }\end{array}$ & 4000 & 80 \\
\hline \multirow{2}{*}{7} & \multirow{2}{*}{$\begin{array}{l}75 \text { \% Cemento } 25 \% \\
\text { Metacaolín }(\mathrm{C}+\mathrm{Mk})\end{array}$} & \multirow{2}{*}{$\begin{array}{l}\text { Material } \\
\text { cementante }\end{array}$} & Cemento tipo Pórtland & 3000 & 75 \\
\hline & & & Metacaolín industrial & 1000 & 25 \\
\hline \multirow{3}{*}{8} & \multirow{3}{*}{$\begin{array}{l}75 \% \text { Cemento } 25 \% \\
\text { Metacaolín + arena } \\
(\mathrm{C}+\mathrm{Mk}+\mathrm{A})\end{array}$} & \multirow{2}{*}{$\begin{array}{c}\text { Material } \\
\text { cementante }\end{array}$} & Cemento tipo Pórtland & 750 & 15 \\
\hline & & & Metacaolín industrial & 250 & 5 \\
\hline & & Agregado & $\begin{array}{l}\text { Arena de Amagá (alto contenido } \\
\text { de cuarzo) }\end{array}$ & 4000 & 80 \\
\hline
\end{tabular}

Una vez se establecen las mezclas de material cementante (cemento tipo Pórtland solo o sustituido parcialmente con arcillas provenientes de RCD, como se muestra en la Tabla 3), se adiciona agregado fino con alto contenido de cuarzo o arena normalizada con el fin de preparar cilindros de prueba (ver Figura 10) y tratar de establecer si en efecto las arcillas provenientes de los RCD tienen propiedades cementicias. 

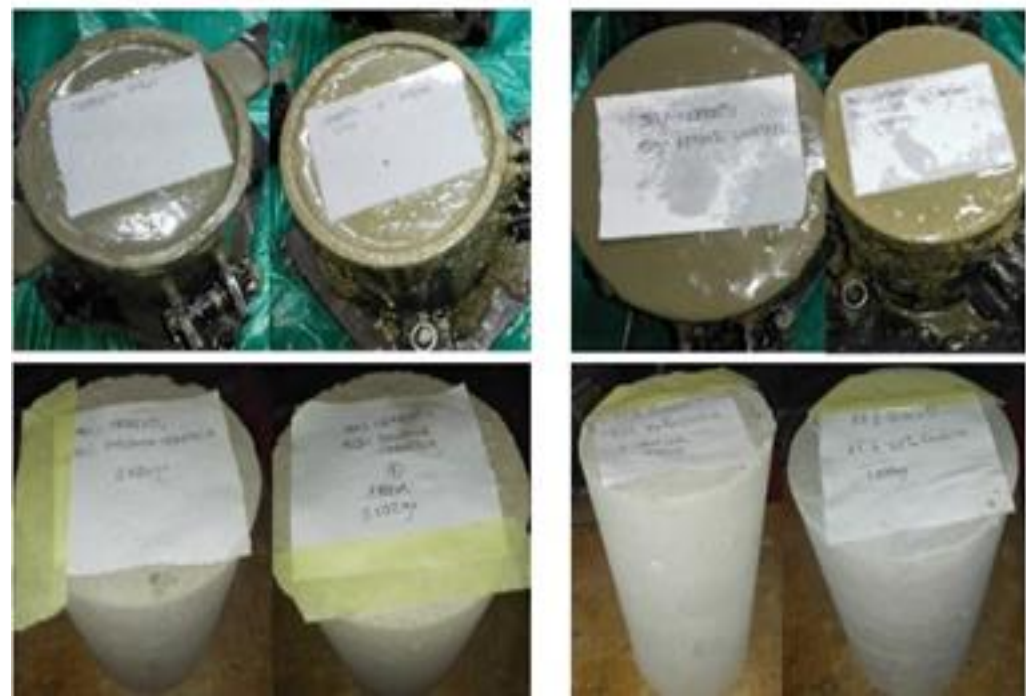

Figura 10. Cilindros de ensayo. Fuente: elaboración propia.

Una vez se realizaron los diferentes cilindros de ensayo, unos solo con material cementante y otros con material cementante y arena, se dejaron en la cámara de curado por 28 días, luego se sometieron a los siguientes ensayos:

Análisis microscópico petrográfico, el cual se encarga de determinar la composición mineralógica de los componentes que hacen parte de la masa solidificada. Si bien esto es una rama especifica de la petrología y busca estudiar la composición de las rocas, es necesario realizar este tipo de ensayos a los especímenes objeto de estudio ya que “...determina la forma y color de los cristales, tipo u origen de cada mineral (primarios o secundarios), la textura, la relación mutua entre los minerales y/o asociaciones minerales, así como la matriz o cementante en caso de que esté presente" [17].

Análisis cuantitativo, "determinación (cuantificación) del contenido de cada uno de los componentes" [18] a través de fluorescencia de rayos X (XRF), que "es una técnica no destructiva utilizada para la evaluación cualitativa y cuantitativa de varios tipos de muestras (agua, suelos, sedimentos, plantas y otros) [19], siendo así útil para determinar el espesor y la composición de capas y recubrimientos.

Difracción de rayos X (DRX), "es una de las técnicas más eficaces para el análisis cualitativo y cuantitativo de fases cristalinas de cualquier tipo de material, tanto natural como sintético" [20].

A través de estos ensayos específicos se puede inferir el comportamiento del material cementante y su relación con los cristales del agregado o arena normalizada.

\section{RESULTADOS Y DISCUSIÓN}

En el análisis petrográfico (ver Tabla 4) se estudiaron solo las pastas cementantes con reemplazo parcial de cerámica proveniente de RCD de aparatos sanitarios y baldosa cerámica por cemento Pórtland, de igual manera reemplazo parcial de Mk por cemento tipo Pórtland.

En la Figura 11 se observan las microfotografías de las mezclas cementicias con sustituciones parciales de polvo cerámico o Mk por cemento tipo Pórtland, en estas se identifican los elementos más representativos de la matriz cementante. Para la mezcla $\mathrm{C}$ se 
logra identificar las partículas de óxidos de hierro, y para las demás mezclas se observan los poros al interior de la matriz cementante y las partículas de cuarzo.
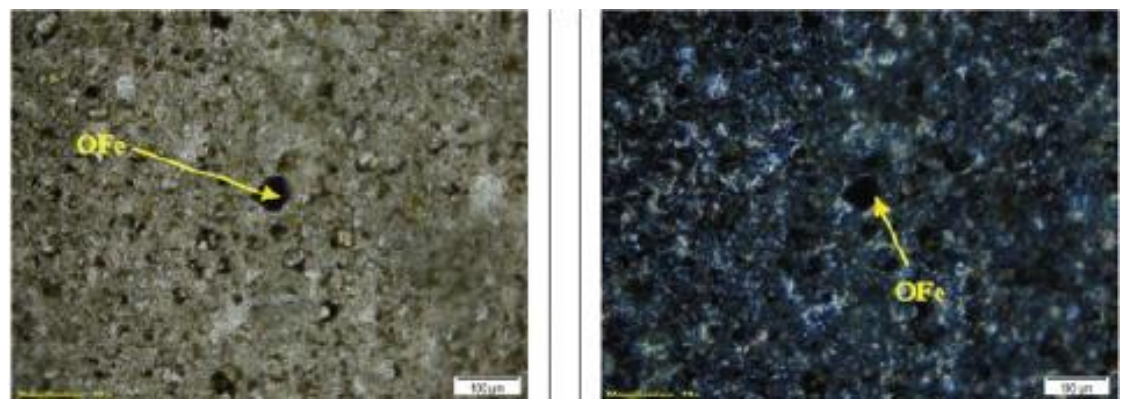

Cemento: Nicoles paralelos y cruzados. Aspecto general del cemento bajo microscopio petrográfico con presencia de partículas menores de cincuenta (50) micras, la mayoría no reconocibles al microscopio. Óxidos de hierro.

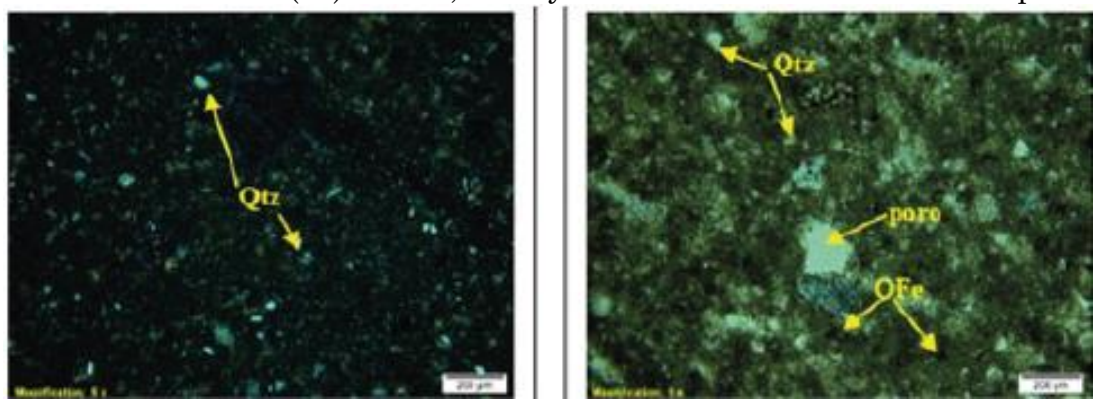

Cemento + aparato sanitario: Nicoles cruzados y paralelos. Aspecto general del cemento bajo microscopio petrográfico, puntos blancos granos de cuarzo tamaño limo (Qtz) y puntos negros de óxido de hierro (OFe).
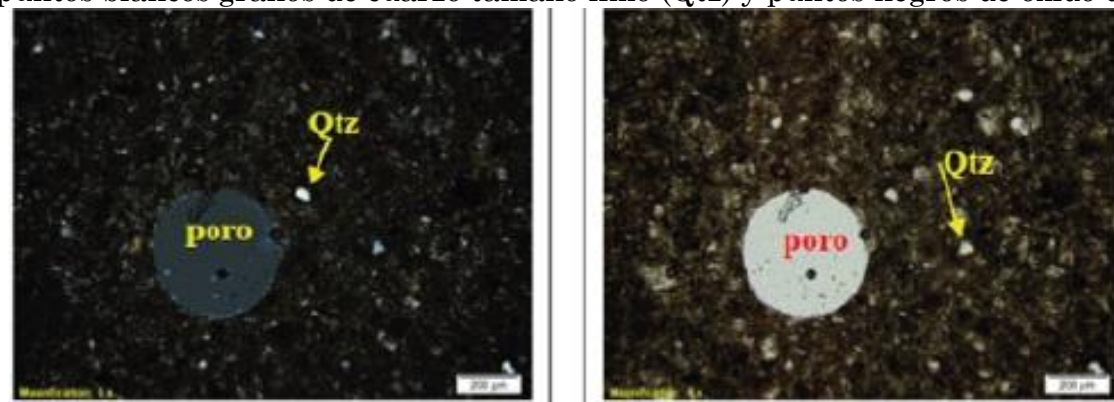

Cemento + baldosa cerámica: Nicoles cruzados y paralelos. Aspecto general del cemento bajo microscopio petrográfico, líneas causadas por el desbaste de la sección, puntos blancos de granos de cuarzo tamaño limo (Qtz) y poro vacío.

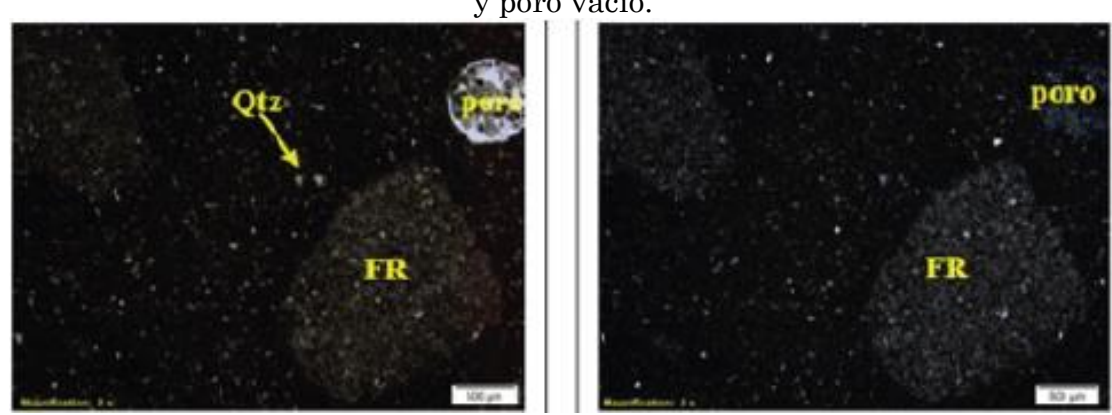

Cemento + Metacaolín: Nicoles paralelos y cruzados. Aspecto general del cemento bajo microscopio petrográfico, puntos blancos de microgramos de cuarzo tamaño limo (Qtz) y fragmentos subangulosos flotantes en el cemento $(\mathrm{FR})$

Figura 11. Microfotografías de matriz cementante. Fuente: elaboración propia. 
Tabla 4. Análisis petrográfico solo matriz cementante. Fuente: elaboración propia.

\begin{tabular}{ccccc}
\hline \multirow{2}{*}{ Componentes } & \multicolumn{4}{c}{ Tipo de mezcla } \\
\cline { 2 - 4 } Matriz & $\mathrm{C}$ & $\mathrm{C}+\mathrm{AS}$ & $\mathrm{C}+\mathrm{B}$ & $\mathrm{C}+\mathrm{Mk}$ \\
Óxidos de hierro & 74,6 & 98,2 & 96,2 & 92,1 \\
Otras micropartículas & 10,4 & 0,7 & 0,5 & 0,6 \\
Cuarzo & 15,0 & 0,0 & 0,0 & 0,0 \\
Poros & Trazas & 1,1 & 2,3 & 3,8 \\
Mk & 0,0 & 0,0 & 1,0 & 1,4 \\
TOTAL & 0,0 & 0,0 & 0,0 & 2,1 \\
& 100,0 & 100,0 & 100,0 & 100,0 \\
\hline
\end{tabular}

En la Figura 12 se muestran las microfotografías de las secciones delgadas del análisis petrográfico para mezclas cementicias con agregado, en estas se pueden observar nicoles paralelos, partículas angulosas de cuarzo, plagioclasas, biotita, feldespato alcalino y líticos granitoides, además del análisis petrográfico de las mezclas adicionadas con áridos, y arena con alto contenido de cuarzo, cuya finalidad es poder contrastar el contenido mineralógico de la pasta cementante con los agregados.

En el análisis petrográfico (ver Tabla 5) se puede observar que la cantidad de cuarzo, palgioclasa, feldespato alcalino para las mezclas $\mathrm{C}+\mathrm{A}$ y $\mathrm{C}+\mathrm{AS}+\mathrm{A}$ son menores en una proporción entre el $49 \%$ y el $52 \%$, minerales característicos de materiales vítreos.

Tabla 5. Análisis petrográfico de matriz cementante con agregado fino. Fuente: elaboración propia.

\begin{tabular}{|c|c|c|c|c|}
\hline \multirow{2}{*}{ Descripción } & \multicolumn{4}{|c|}{ Tipo de mezcla } \\
\hline & $\mathrm{C}+\mathrm{A}$ & $\mathrm{C}+\mathrm{AS}+\mathrm{A}$ & $\mathrm{C}+\mathrm{B}+\mathrm{A}$ & $\mathrm{C}+\mathrm{Mk}+\mathrm{A}$ \\
\hline \multicolumn{5}{|c|}{ Fragmentos de minerales: \% } \\
\hline Cuarzo & 8,8 & 9,7 & 17,3 & 12,7 \\
\hline Plagioclasa & 5,1 & 4,9 & 14,2 & 9,3 \\
\hline Feldespato alcalino & 13,2 & 13,0 & 20,5 & 15,4 \\
\hline Biotita & 0,7 & 2,4 & 1,6 & 1,7 \\
\hline Epidota & Trazas & Trazas & 0,0 & 0,0 \\
\hline Opacos & Trazas & Trazas & 0,6 & Trazas \\
\hline \multicolumn{5}{|c|}{ Fragmentos líticos (\%) } \\
\hline Granitos & 28,7 & 27,6 & 5,7 & 22,9 \\
\hline \multicolumn{5}{|c|}{ Otros $(\%)$} \\
\hline Poros & 2,2 & 1,6 & 0,7 & 0,8 \\
\hline Fragmentos de baldosa & 0,0 & 0,0 & Trazas & 0,0 \\
\hline \multicolumn{5}{|c|}{ Matriz (\%) } \\
\hline Cemento & 32,2 & 27,1 & 39,4 & 37,2 \\
\hline Fragmentos $<550$ micras & 9,1 & 0,0 & 0,0 & 0,0 \\
\hline Granos & 0,0 & 13,7 & 0,0 & 0,0 \\
\hline TOTAL & 100,0 & 100,0 & 100,0 & 100,0 \\
\hline
\end{tabular}



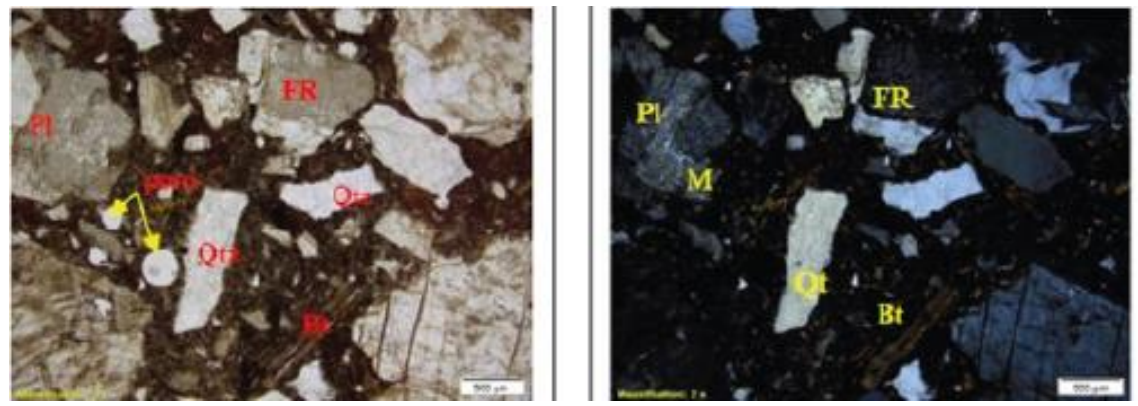

Cemento + arena: Nicoles paralelos y cruzados. Aspecto general del concreto, granos angulosos de cuarzo (Qtz), plagioclasa (p1), escasas 1 líticos graníticos (Fr) mal seleccionados y cementados por una matriz de color pardo con granos de tamaño limo (M).
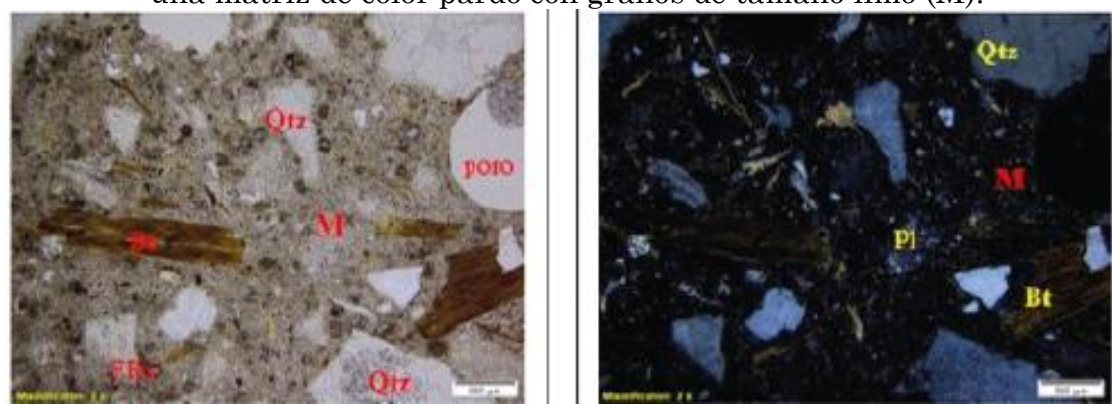

Cemento + aparato sanitario + arena: Nicoles paralelos y cruzados. Aspecto general de la matriz, constituida por cemento y granos angulosos de cuarzo (Qtz), plagioclasa (p1), biotita (Br) mal seleccionados y flotantes en el cemento (c). Poros circulares locales.
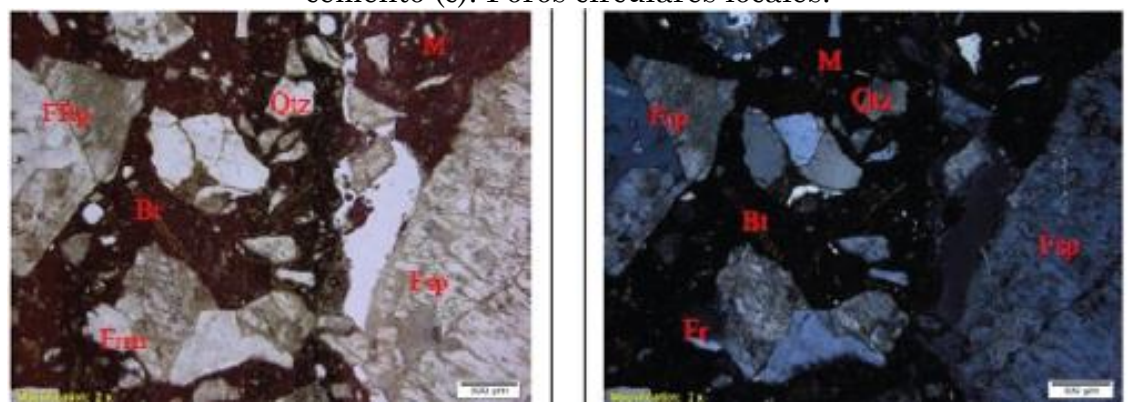

Cemento + metacaolín + arena: Nicoles paralelos y cruzados. Granos angulosos de cuarzo (Qtz), plagioclasa (P1) feldespato alcalino (Fsp), láminas de biotita (Bt) y líticos plutónicos granitoides (FRp) flotantes en matriz afanitica de color pardo (M)
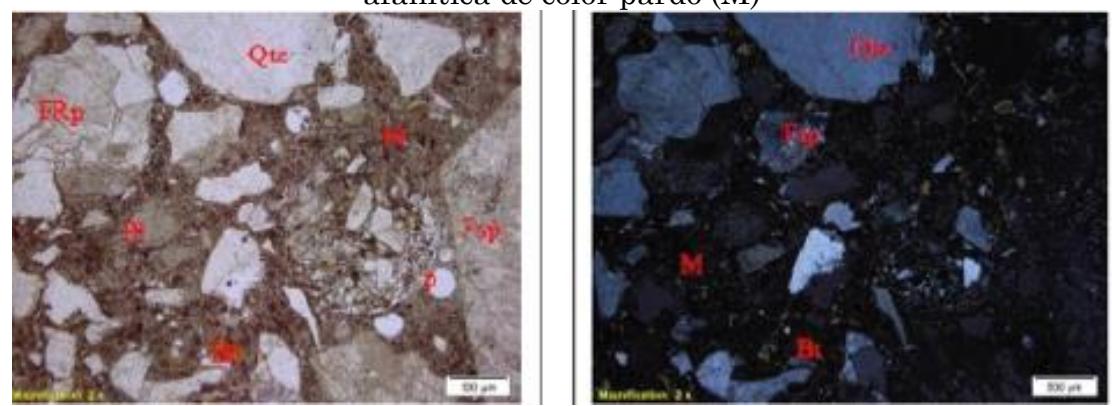

Cemento + baldosa cerámica + arena: Nicoles paralelos y cruzados. Aspecto general del concreto, granos angulosos de cuarzo (Qtz), plagioclasa (Pl), feldespato alcalino (Fsp), líticos granitoides (Frp) mal seleccionados y cementados por una matriz de color pardo con granos de tamaño limo (M) y escasos poros.

Figura 12. Microfotografías matriz cementante con agregado. Fuente: elaboración propia. 
$\mathrm{El}$ análisis químico cuantitativo obtenido por la fluorescencia de rayos $\mathrm{X}$ en las mezclas $\mathrm{C}$, $\mathrm{C}+\mathrm{AS}, \mathrm{C}+\mathrm{B}$ y $\mathrm{C}+\mathrm{Mk}$, tuvo su mayor cambio en el silicio, aluminio y calcio contenido en las mezclas, tal como se muestra en la Tabla 6.

Tabla 6. Análisis químico cuantitativo a partir de fluorescencia de rayos X, solo matriz cementante. Fuente: elaboración propia.

\begin{tabular}{lcccc}
\hline \multirow{2}{*}{ Elemento contenido en \% } & \multicolumn{2}{c}{ Tipo de mezcla } & & \\
\cline { 2 - 5 } & $\mathrm{C}$ & $\mathrm{C}+\mathrm{AS}$ & $\mathrm{C}+\mathrm{B}$ & $\mathrm{C}+\mathrm{Mk}$ \\
\hline Silicio, expresado como $\mathrm{SiO}_{2}$ & 16,80 & 42,07 & 38,63 & 22,61 \\
Titanio, expresado como $\mathrm{TiO}_{2}$ & 0,21 & 0,47 & 0,42 & 0,40 \\
Aluminio, expresado como $\mathrm{Al}_{2} \mathrm{O}_{3}$ & 4,75 & 12,66 & 10,49 & 9,51 \\
Hierro, expresado como $\mathrm{Fe}_{2} \mathrm{O}_{3}$ & 2,40 & 2,28 & 3,28 & 2,05 \\
Manganeso, expresado como $\mathrm{MnO}$ & 0,03 & 0,03 & 0,05 & 0,03 \\
Magnesio, expresado como $\mathrm{MgO}$ & 1,50 & 1,03 & 1,59 & 1,60 \\
Calcio, expresado como $\mathrm{CaO}_{\text {Sodio, expresado como } \mathrm{Na} 2 \mathrm{O}}$ & 43,64 & 26,43 & 23,26 & 33,25 \\
Potasio, expresado como $\mathrm{K}_{2} \mathrm{O}$ & 0,56 & 1,05 & 0,84 & 0,43 \\
Fósforo, expresado como $\mathrm{P}_{2} \mathrm{O}_{5}$ & 0,53 & 1,75 & 1,31 & 0,45 \\
Azufre, expresado como $\mathrm{SO}_{3}$ & 0,09 & 0,14 & 0,09 & 0,08 \\
PPI (Pérdidas por Ignición de $105^{\circ} \mathrm{C}$ a $\left.100{ }^{\circ} \mathrm{C}\right)$ & 26,85 & 10,24 & 18,64 & 27,75 \\
\hline
\end{tabular}

El silicio y el aluminio contenido en la mezcla $\mathrm{C}$, es mucho más bajo que los contenidos en las mezclas $\mathrm{C}+\mathrm{AS}, \mathrm{C}+\mathrm{B}$ y $\mathrm{C}+\mathrm{Mk}$ hasta en 2,50 veces; sin embargo, la cantidad de calcio contenido en la mezcla $\mathrm{C}$ es mucho más alto que el calcio contenido en las mezclas $\mathrm{C}+\mathrm{AS}, \mathrm{C}+\mathrm{B}$ y C+Mk hasta en 1,8 veces.

Cuando la matriz cementante contiene agregados finos con alto contenido de cuarzo, las muestras reportan datos químicos más estables en cuanto a la varianza que los reportados en el análisis solo de la matriz cementante.

Como se puede ver en la Tabla 7, los elementos químicos con cambios más significativos entre las muestras analizadas son el calcio y el azufre, donde el contenido de calcio en la mezcla $\mathrm{C}+\mathrm{A}$ es superior el 1,8 veces con respecto a la mezcla $\mathrm{C}+\mathrm{B}+\mathrm{A} ; 1,7$ veces, con respecto a $\mathrm{C}+\mathrm{AS}+\mathrm{A} ; 1,4$ veces, con respecto a $\mathrm{C}+\mathrm{Mk}+\mathrm{A}$. Por su parte, el contenido de azufre en la mezcla $\mathrm{C}$ es evidentemente mayor que las demás mezclas. Además, se observa homogeneidad en el contenido de silicio de las muestras, esto puede ser por el contenido incorporado de agregados finos con alto contenido de cuarzo.

El análisis mineralógico por difracción de rayos X, DRX, usó el método Rietveld, el cual se obtiene por procedimientos matemáticos de mínimos cuadrados derivados de muestras de referencia puras. En la fase analítica no se utilizó ningún tipo de estándar para obtener los resultados cuantitativos, debido que se realiza un análisis comparativo con los resultados arrojados.

En las Figuras 13 a la 16 se puede observar el análisis mineralógico de la matriz cementante sin adición de agregado para las mezclas $\mathrm{C}, \mathrm{C}+\mathrm{AS}, \mathrm{C}+\mathrm{B}$ y $\mathrm{C}+\mathrm{Mk}$. 
Tabla 7. Análisis químico cuantitativo a partir de fluorescencia de rayos X de la matriz cementante con agregado fino. Fuente: elaboración propia.

Elemento contenido en \%

Silicio, expresado como $\mathrm{SiO}_{2}$

Titanio, expresado como $\mathrm{TiO}_{2}$

Aluminio, expresado como $\mathrm{Al}_{2} \mathrm{O}_{3}$

Hierro, expresado como $\mathrm{Fe}_{2} \mathrm{O}_{3}$

Manganeso, expresado como $\mathrm{MnO}$

Magnesio, expresado como $\mathrm{MgO}$

Calcio, expresado como $\mathrm{CaO}$

Sodio, expresado como $\mathrm{Na}_{2} \mathrm{O}$

Potasio, expresado como $\mathrm{K}_{2} \mathrm{O}$

Fósforo, expresado como $\mathrm{P}_{2} \mathrm{O}_{5}$

Azufre, expresado como $\mathrm{SO}_{3}$

PPI (Pérdidas por Ignición de $105^{\circ} \mathrm{C}$ a $1000{ }^{\circ} \mathrm{C}$ )

\begin{tabular}{cccc}
\multicolumn{4}{c}{ Tipo de mezcla } \\
\hline $\mathrm{C}+\mathrm{A}$ & $\mathrm{C}+\mathrm{AS}+\mathrm{A}$ & $\mathrm{C}+\mathrm{B}+\mathrm{A}$ & $\mathrm{C}+\mathrm{Mk}+\mathrm{A}$ \\
65,34 & 69,54 & 68,10 & 65,94 \\
0,23 & 0,29 & 0,28 & 0,29 \\
10,08 & 11,69 & 11,27 & 10,54 \\
1,69 & 1,63 & 1,74 & 1,49 \\
0,03 & 0,04 & 0,04 & 0,03 \\
0,46 & 0,33 & 0,44 & 0,45 \\
9,94 & 5,79 & 5,36 & 6,89 \\
1,75 & 1,81 & 2,17 & 1,77 \\
4,27 & 4,47 & 4,84 & 4,21 \\
0,03 & 0,04 & 0,04 & 0,03 \\
0,44 & 0,12 & 0,16 & 0,23 \\
5,49 & 3,99 & 5,38 & 7,65
\end{tabular}

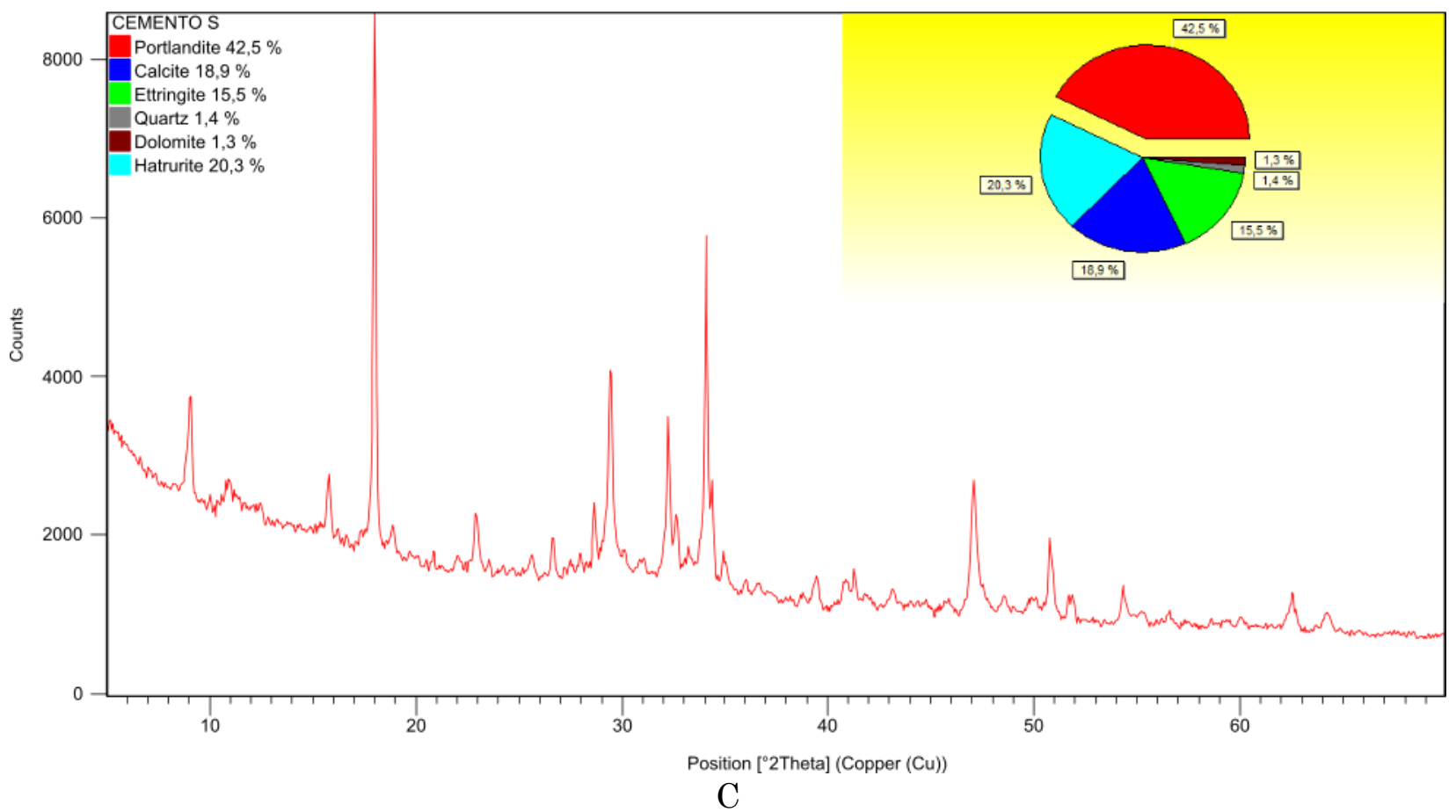

Figura 13. DRX matriz cementante en cemento (C). Fuente: elaboración propia. 


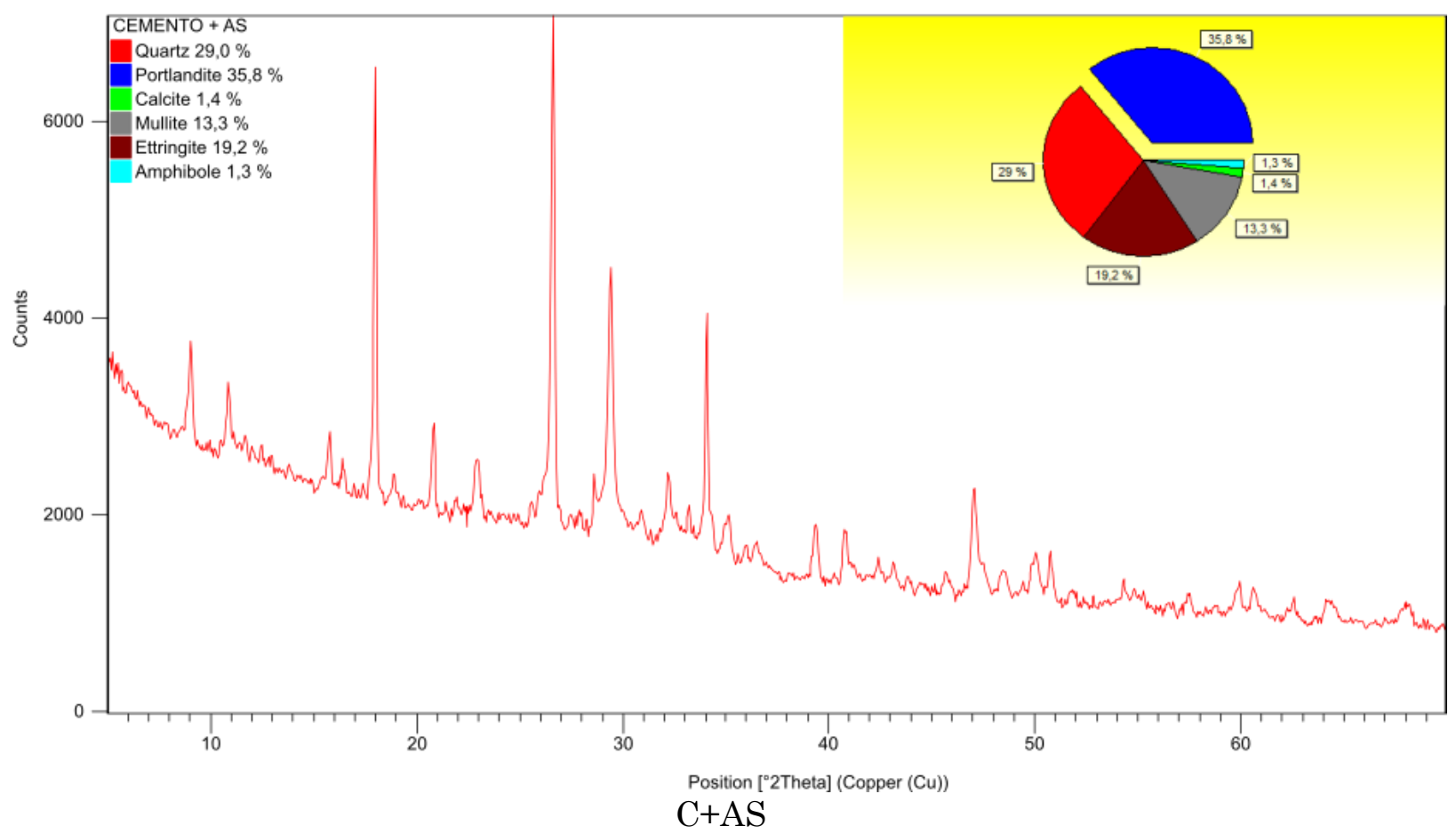

Figura 14. DRX matriz cementante $50 \%$ Cemento $50 \%$ aparato sanitario (C+AS)

Fuente: elaboración propia.

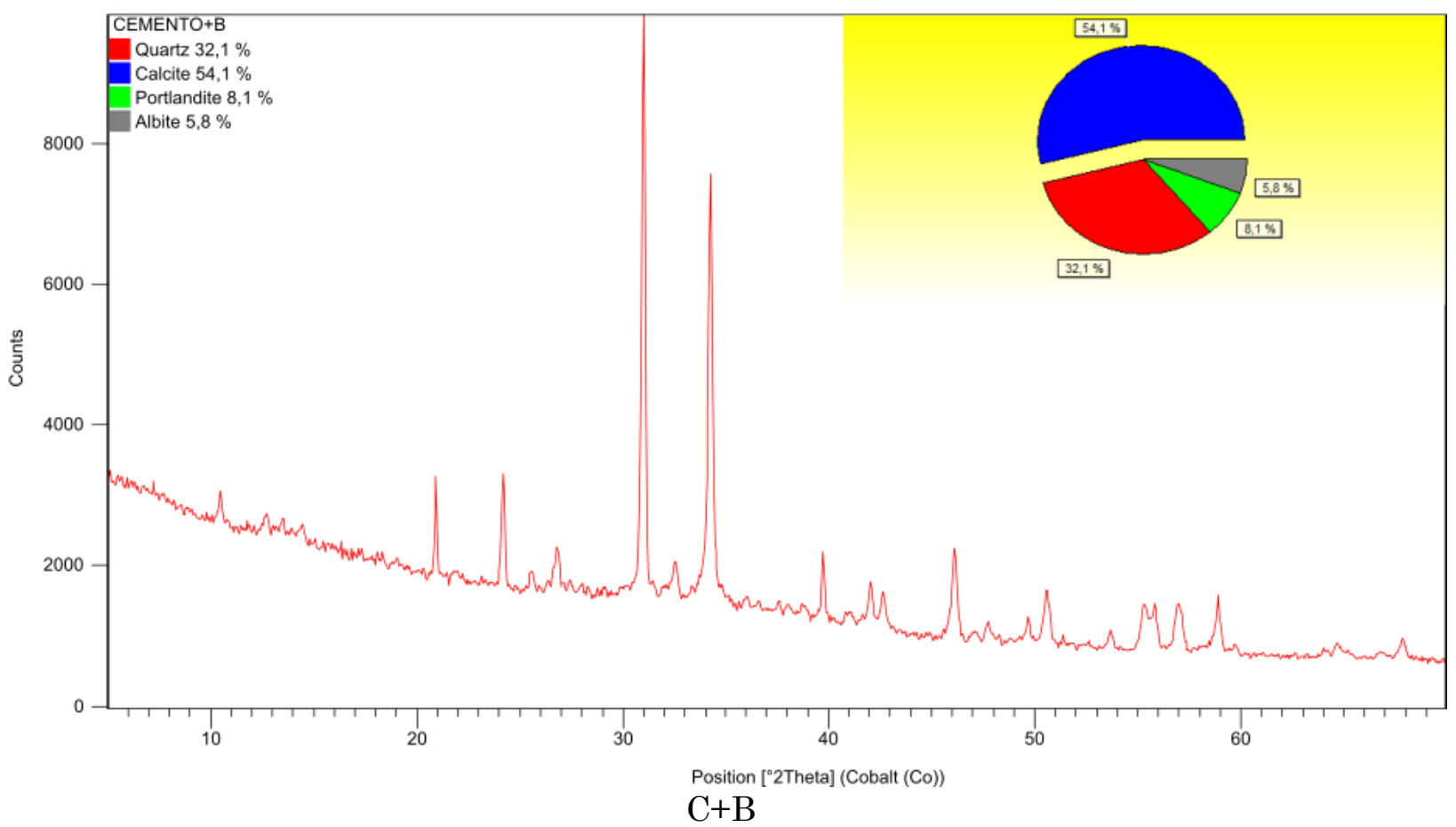

Figura 15. DRX matriz cementante $50 \%$ Cemento $50 \%$ baldosa cerámica Fuente: elaboración propia. 


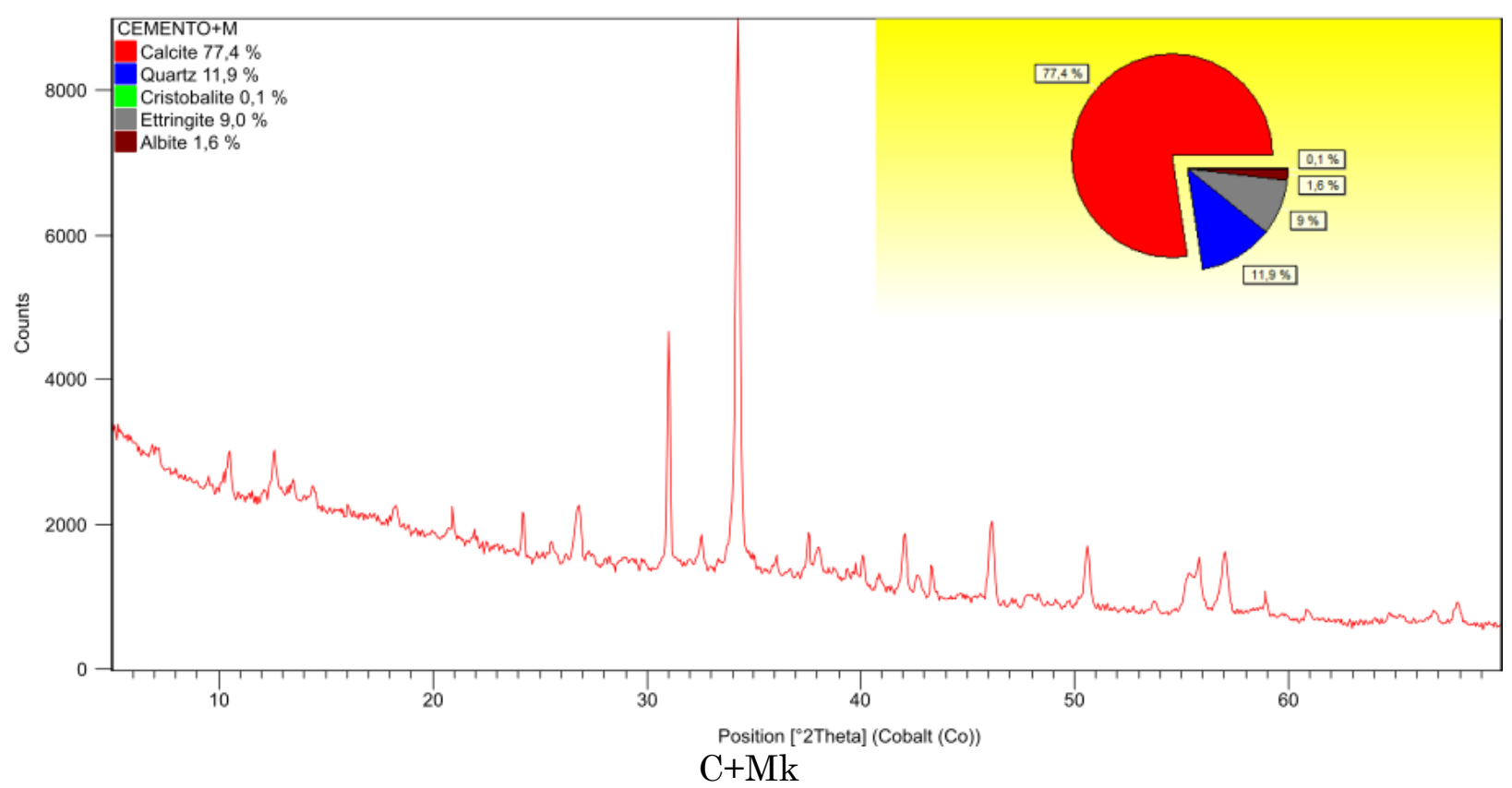

Figura 16. DRX matriz cementante $75 \%$ Cemento $25 \%$ Metacaolín (C+Mk)

Fuente: elaboración propia.

Las muestras indican que la mezcla $\mathrm{C}$ tiene un alto contenido de portlandita, calcita y hatrurite, con 42,5\%, 18,9\% y 20,3\%, respectivamente; es decir un 81,7 \% de contenido asociado a materiales cementicios con altos contenidos de hidróxido de calcio, carbonato de calcio y calcio, silicio y oxígeno. La mezcla C+AS contiene en mayores proporciones $35,8 \%$ de portlandita (hidróxido de calcio), 19,2\% de etringita (sulfoaluminato de calcio hidratado), $13,3 \%$ de mullita (material cerámico) y $29 \%$ de cuarzo; es decir que solo el $55 \%$ del total de la matriz cementante podría ser activado como material cementante tipo hidráulico.

En la mezcla C+B se tiene el 32\% de cuarzo, 54,1\% de calcita, solo un 8, $1 \%$ de portlandita y un $5,8 \%$ de albita (plagioclasas). La mezcla $\mathrm{C}+\mathrm{Mk}$ contiene en mayor proporción calcita, con un 77,4 \%, 11,9 \% cuarzo, $9 \%$ etringita y 1,6 \% de albita. Es de suponer que las propiedades cementicias de la matriz $\mathrm{C}+\mathrm{Mk}$ son mayores que para la matriz $\mathrm{C}+\mathrm{B}$, puesto que los componentes con mayor contenido de calcio se encuentran en la segunda matriz.

La cantidad de cuarzo en las cuatro muestras (ver Figuras del 17 al 20) oscila entre un $27,5 \%$ y un $37,6 \%$. Solo se reportó presencia de portlandita en la muestra C+A (11\%) y en $\mathrm{C}+\mathrm{AS}+\mathrm{A}(4,4 \%)$; la presencia de albita se identificó en 3 de las 4 muestras de la siguiente manera: C+A (24,8 \%), C+AS+A (17,1\%) y C+Mk+A (31,2\%). En cambio, la microclina y el aluminosilicato de potasio se encuentra en tres muestras, en la C+A (29\%), C+AS+A (24,3\%) y en $\mathrm{C}+\mathrm{B}+\mathrm{A}(20,5 \%)$. En la muestra $\mathrm{C}+\mathrm{Mk}+\mathrm{A}$ no se presenta. 


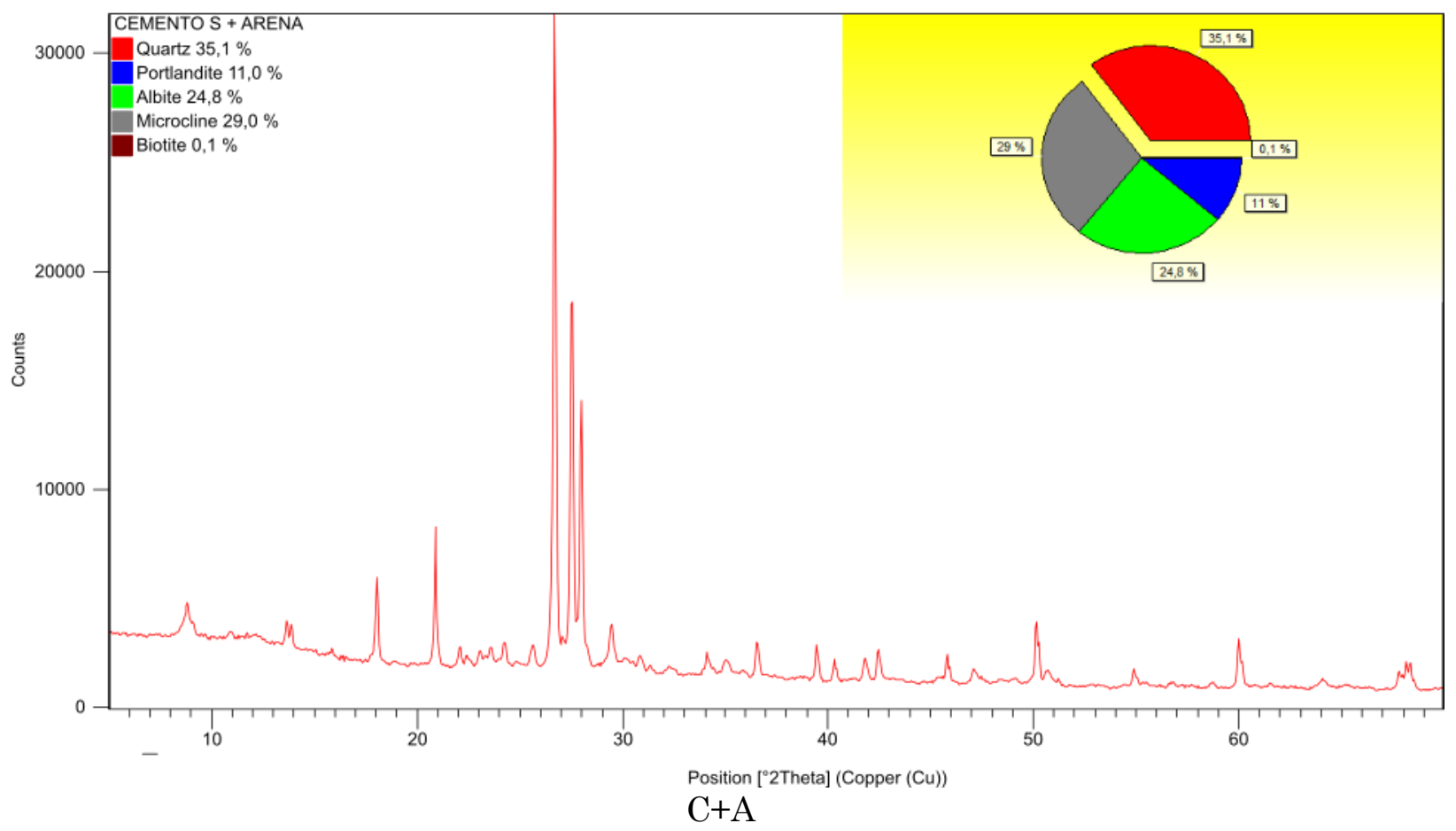

Figura 17. DRX matriz cementante con agregado fino en 100\% Cemento + arena (C+A)

Fuente: elaboración propia.

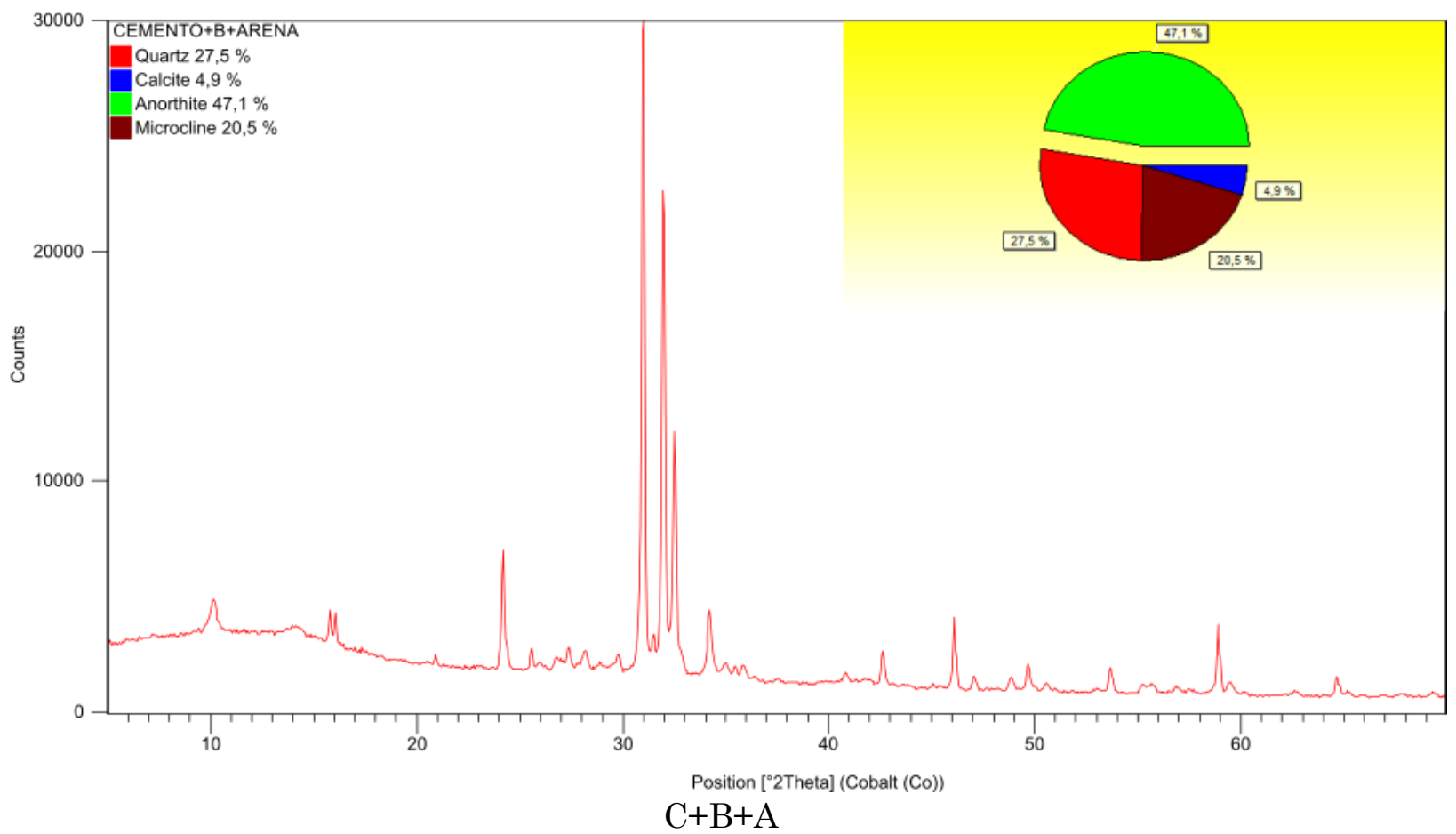

Figura 18. DRX matriz cementante con agregado fino en $50 \%$ Cemento $50 \%$ baldosa cerámica + arena $(\mathrm{C}+\mathrm{B}+\mathrm{A})$. Fuente: elaboración propia. 


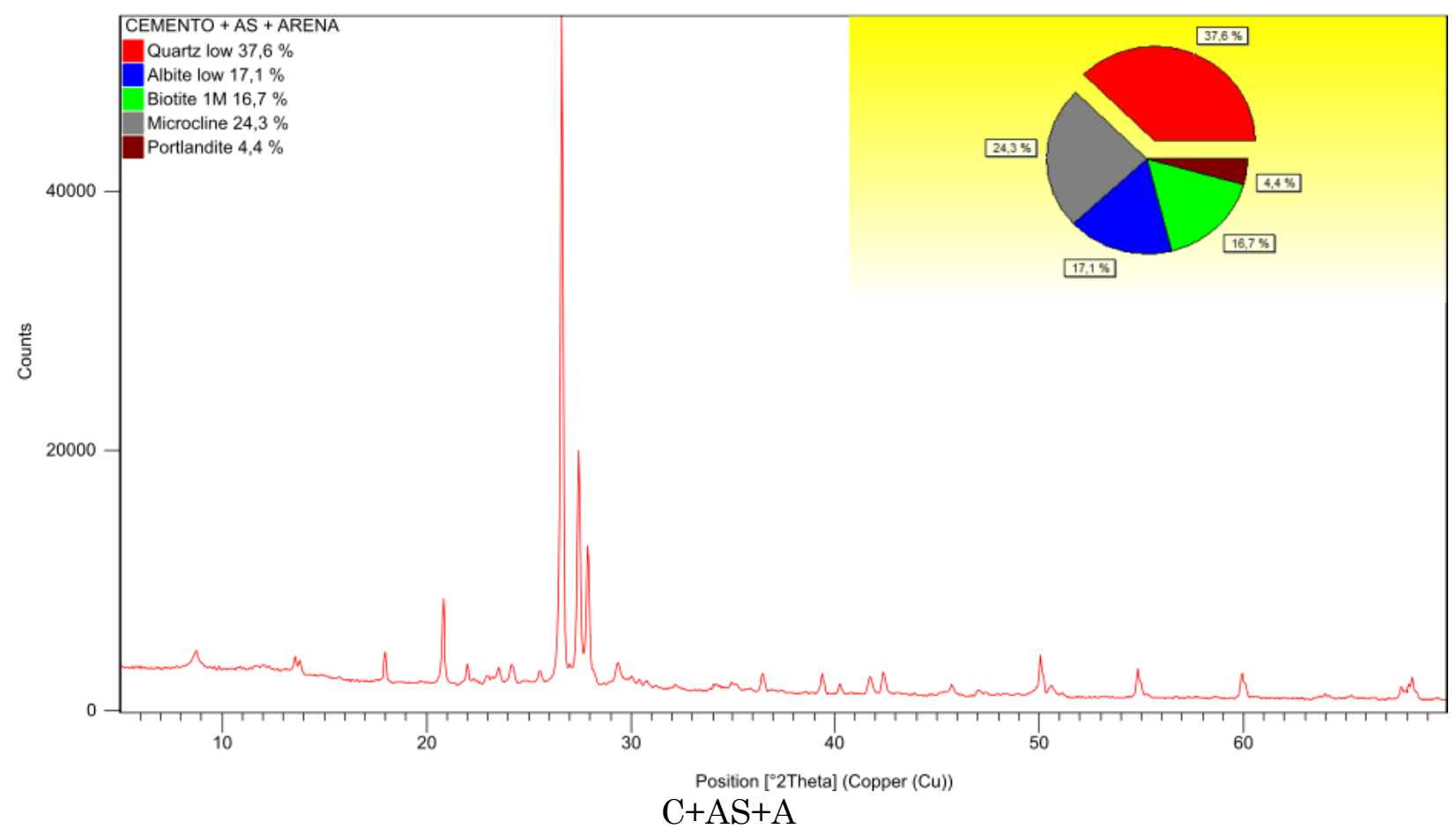

Figura 19. DRX matriz cementante con agregado fino en $50 \%$ Cemento $50 \%$ aparato sanitario + arena $(\mathrm{C}+\mathrm{AS}+\mathrm{A})$. Fuente: elaboración propia.

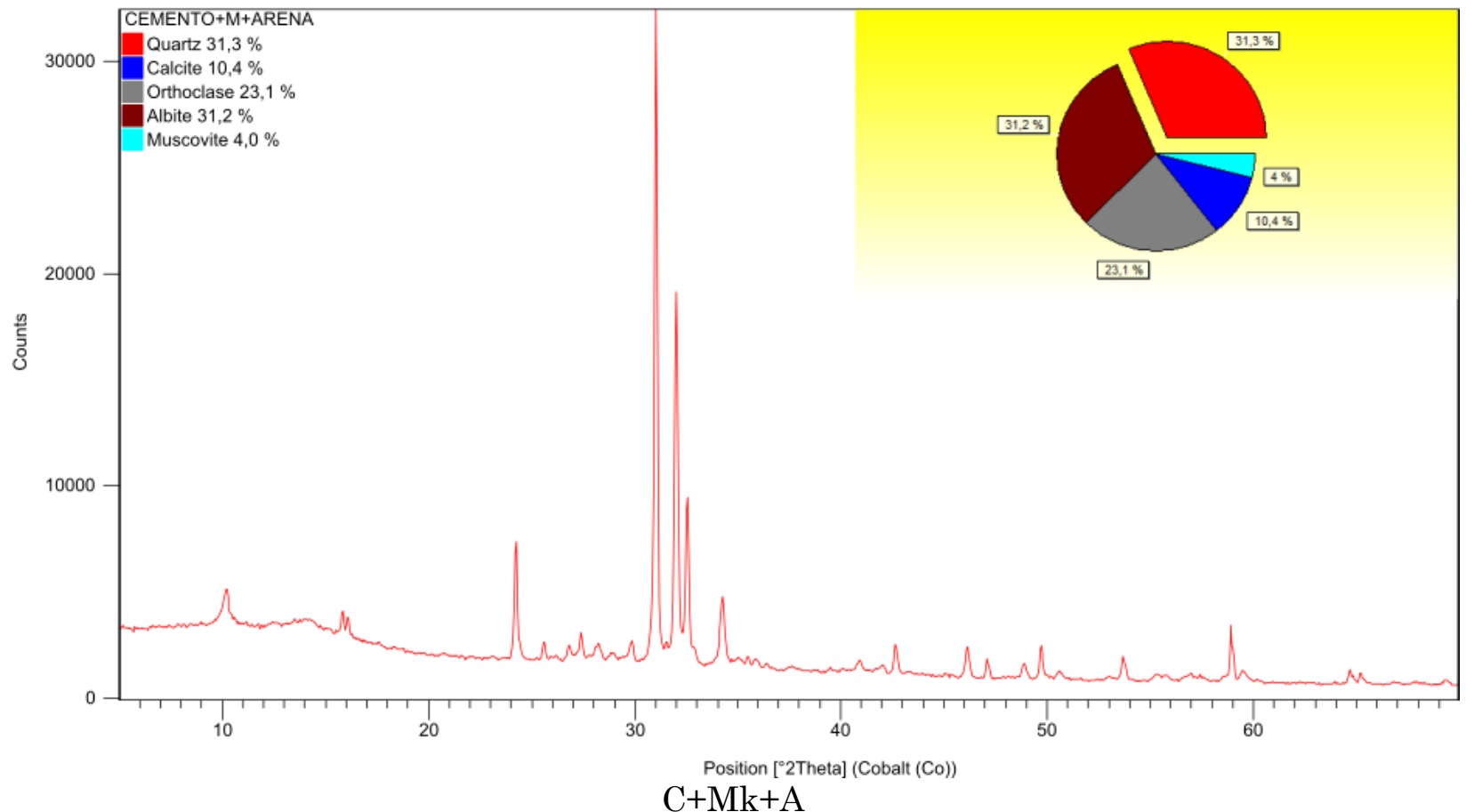

Figura 20. DRX matriz cementante con agregado fino en 75 \% Cemento $25 \%$ Metacaolín (C+Mk) Fuente: elaboración propia. 


\section{CONCLUSIONES}

A partir de los análisis petrográficos, químico cuantitativo a través de FRX y mineralógico a partir de DRX, realizados a las muestras identificadas en la Tabla 3, se obtuvieron los siguientes resultados:

La cantidad de matriz cementante para la muestra de solo cemento tipo Pórtland, C, es menor que en las demás muestras; sin embargo, la muestra de $\mathrm{C}$ tiene un alto contenido de óxido de hierro comparado con las demás muestras. Por otra parte, el contenido de cuarzo para la muestra $\mathrm{C}$ es inferior que, en las demás muestras, lo que implica que el mineral de cuarzo si bien puede mejorar propiedades mecánicas en la pasta de cemento, no reacciona como material cementante.

$\mathrm{Al}$ adicionarle agregado fino a la matriz cementante se puede observar que la mezcla $\mathrm{C}+\mathrm{A}$ contiene un $32,2 \%$ de matriz cementante y un $9,1 \%$ de fragmentos con tamaños inferiores a las 50 micras, obteniendo un valor global de 41,3\% de matriz cementante. Para la mezcla $\mathrm{C}+\mathrm{AS}+\mathrm{A}$ se obtuvo un $27,1 \%$ de matriz cementante y un $13,7 \%$ de granos para un global de $40,8 \%$ de matriz cementante. Si bien los valores globales de ambos resultados son similares, no se podría determinar que en efecto los granos contenidos en la mezcla C+AS+A actúan como cementante recubriendo los agregados finos, no obstante, sí si se puede afirmar que esta cantidad adicional de granos mejora las condiciones de resistencia a esfuerzos de compresión del concreto en edades tempranas.

De acuerdo con análisis químico cuantitativo obtenido a través de fluorescencia de rayos $\mathrm{X}$, se pudo identificar que las mezclas de solo matriz cementante preparadas únicamente con cemento tipo Pórtland, $\mathrm{C}$, tienen un mayor contenido de calcio que las mezclas sustituidas parcialmente con polvo cerámico proveniente de los $\mathrm{RCD}, \mathrm{C}+\mathrm{AS}$ y $\mathrm{C}+\mathrm{B}$ y que la mezcla sustituida parcialmente con metacaolín, Mk. Esto mejoró la resistencia al esfuerzo a la compresión ya que "al realizar reemplazos de MK por cemento con porcentajes del 10\%, se logran los máximos valores de resistencias a compresión” [16].

Según los ensayos de DRX, se puede inferir que existe potencial cementante en los cerámicos de baldosa y de aparatos sanitarios provenientes de los RCD, ya que, si bien no se pudo determinar su potencial cementante, hay contenidos químicos en estas mezclas, que tratadas, podrían activarse y reaccionar químicamente para mantener unidos los agregados.

Los residuos cerámicos del ladrillo pueden ser utilizados como material agregado para morteros en actividades de mampostería y de revoques o enlucidos, e incluso es posible sustituir has el $5 \%$ del cemento tipo Pórtland por polvo de ladrillo cerámico para estas actividades.

Según los resultados obtenidos, los RCD provenientes de baldosa cerámica y aparatos sanitarios poseen un alto potencial para ser utilizados en mezclas de concreto ya sea como agregado fino o en la pasta cementante. Los tamaños de las partículas de RCD de baldosa cerámica y aparatos sanitarios para ser utilizados en la pasta cementante deben ser inferiores a 74 micras, lo ideal sería que tuviesen un tamaño inferior a las 20 micras (más pequeñas que las partículas del cemento tipo Pórtland), con el fin que puedan actuar en los espacios vacíos dejados por las partículas de la pasta cementicia. Si bien no fue posible determinar la reacción cementante del polvo de baldosa cerámica y de aparatos sanitarios, se puede decir que es posible su utilización en adiciones cementantes como relleno, debido a que la adición en proporciones de hasta el 50\% aumentan la reología del material.

En una segunda fase de la presente investigación será necesario evaluar los ciclos del material cementante y definir si en efecto los cerámicos provenientes de los RCD tienen propiedades cementicias, y establecer así si su activación química de verdad se logra solo con el contacto al cemento tipo Pórtland o se hace necesario otro tipo de tratamiento antes de 
someterlo a reacciones químicas. De igual manera se deben ampliar a mínimo cuatro las repeticiones de los ensayos desde la metodología.

\section{AGRADECIMIENTOS}

Artículo de investigación científica derivado del proyecto de investigación "Evaluación técnica, económica y ambiental de concretos elaborados con arcillas provenientes de los RCD's como sustituyente parcial del cementante", financiado por la Universidad de San Buenaventura Medellín, el grupo de investigación Hombre, proyecto y ciudad, en la línea Bienestar humano y tecnología, y la Institución Universitaria Colegio Mayor de Antioquia, grupo de investigación Ambiente, hábitat y sostenibilidad, en la línea de tecnología de la construcción. La investigación tuvo apoyo financiero de ambas instituciones en el marco de las convocatorias internas para investigación. Año de inicio: 2016; año de finalización: 2017. Adicionalmente, agradecer a la entidad Ingeo Ensayos Medellín, donde se realizaron los ensayos respectivos para el proceso de esta investigación.

\section{CONFLICTOS DE INTERÉS DE LOS AUTORES}

Los autores declaran no tener ningún conflicto de interés.

\section{CONTRIBUCIÓN DE LOS AUTORES}

Carlos Alberto Mejía-Barrera contribuyó en la formulación del proyecto, preparación de muestras, diseño de mezclas, ensayos, redacción del informe de investigación, resultados, conclusiones y corrección del presente artículo.

Sergio Andrés Arboleda-López contribuyó en la formulación del proyecto, la logística operativa de consecución, trituración y tamizaje de los RCD, en la escritura de la metodología y correcciones al presente artículo.

Ubany de Jesús Zuluaga-de los Ríos contribuyó en la caracterización de materiales, diseño de mezclas, análisis físico de las muestras, análisis de resultados obtenidos y conclusiones.

Luis Javier Sierra-Arango contribuyó en la formulación del proyecto, en la logística para la realización de los ensayos, escritura de resultados y corrección del presente artículo.

\section{REFERENCIAS}

[1] F. G. Díaz, "Realcalinización electroquímica del concreto reforzado carbonatado: una opción de prevención contra la corrosión”, (Tesis Doctorado), Facultad de Ingeniería Civil, Universidad Autónoma de Nuevo León, Nuevo León. 2010. http://eprints.uanl.mx/2142/1/1080177800.pdf

[2] C. A. Mejía Barrera, "Receptores de impactos: Una mirada desde el extractivismo hacia las comunidades cercanas a los lugares donde se extraen agregados pétreos para la confección de concreto", (Tesis de Maestría), Facultad de Arquitectura, Área Curricular de Construcción y Hábitat, Universidad Nacional de Colombia, Medellín, 2014. https://repositorio.unal.edu.co/bitstream/handle/unal/75136/98701292.2014.pdf?sequence=1\&isAllowed=y

[3] L. Gutiérrez de López, El concreto y otros materiales para la construcción, Facultad de Ingeniería y Arquitectura Departamento de Ingeniería Civil. Universidad Nacional de Colombia. 2003. https://repositorio.unal.edu.co/bitstream/handle/unal/9302/9589322824_Parte2.pdf?sequence=9\&isAllowe $\underline{\mathrm{d}=\mathrm{y}}$ 
[4] CAMACOL, "Colombia construcción en cifras octubre 2021”, Bogotá, 2021.

[5] L. M. Vélez, "Permeabilidad y porosisdad en concreto", Rev. TecnoLógicas, no. 25, pp. 169-187, Dic. 2010. https://repositorio.itm.edu.co/handle/20.500.12622/869

[6] F. Puertas; A. Barba; M. F. Gazulla; M. P. Gómez; M. Palacios; S. Martínez Ramírez, "Residuos cerámicos para su posible uso como materia prima en la fabricación de clínker de cemento portland: caracterización y activación alcalina”, materconstrucc, vol. 56, no. 281, pp. 73-84, Ene. 2006. https://materconstrucc.revistas.csic.es/index.php/materconstrucc/article/view/94/134

[7] C. Hendriks; E. Worrell; D. de Jager; K. Blok. "Emission Reduction of Greenhouse Gases from Cement Industry", In Greenhouse Gas Control Technologies 4, 2004. https://doi.org/10.1016/B978-008043018$\underline{8 / 50150-8}$

[8] E. Mejía; J. Giraldo; L. Martínez, "Residuos de construcción y demolición. Revisión sobre su composición, impactos y gestión”, Rev. CINTEX, vol. 18, pp. 105-130, Jul. 2013. https://revistas.pascualbravo.edu.co/index.php/cintex/article/view/52/54

[9] A. Enshassi; B. Kochendoerfer; E. Rizq, "An evaluation of environmental impacts of construction projects", Rev. Ing. Construcción RIC, vol. 29, no. 3, pp. 234-254, Nov. 2014. https://scielo.conicyt.cl/pdf/ric/v29n3/en_art02.pdf

[10] M. I. Ramírez Rojas, "Sostenibilidad de la explotación de materiales de construcción en el Valle de Aburrá", (Tesis de Maestría), Universidad Nacional de Colombia, Medellín, 2008. https://repositorio.unal.edu.co/bitstream/handle/unal/2591/43207166_2009.pdf?sequence=1\&isAllowed=y

[11] E. Beltrán Castillo; V. H. Ortiz Ariza, "Estudio del comportamiento de la mezcla de agregados adicionados con el 3.5, 4.5 y 5.5 de limalla fina, para las mezclas de concreto”, (Trabajo de Grado), Facultad de Ingeniería Civil, Universidad Pontificia Bolivariana, Bucaramanga, 2010. https://repository.upb.edu.co/bitstream/handle/20.500.11912/1357/digital_19868.pdf?sequence=1\&isAllowe $\mathrm{d}=\mathrm{y}$

[12] R. Mejía de Gutiérrez; C. Rodríguez; E. Rodríguez; J. Torres; S. Delvasto, "Concreto adicionado con Metacaolín: Comportamiento a carbonatación y cloruros", Rev. Fac. Ing. Univ. Antioquia, no. 48, pp. 55-64, Jun. 2009. http://www.scielo.org.co/pdf/rfiua/n48/n48a06.pdf

[13] A. Tironi, "Materiales cementicios de baja energía. Activación térmica de arcillas, relación entre estructura y actividad puzolánica", (Tesis Doctorado), Facultad de Ciencias Exactas Departamento de Química, Universidad de La plata, 2013. http://sedici.unlp.edu.ar/bitstream/handle/10915/26504/Documento_completo.pdf?sequence=1\&isAllowed= y

[14] J. F. Muñoz; I. Tejedor; M. A. Anderson; S. M. Cramer, "Innovative Pavement Research Foundation Airport Concrete Pavement Technology Program Effects of Coarse Aggregate Clay-Coatings on Concrete Performance," 2005. 4\%202\%20Clay\%20Dispersion\%20Final\%20Report.pdf

[15] J. F. Muñoz, K.; S. M. Cramer; M. I. Tejedor; M. A. Anderson, "Effects of Coarse Aggregate Clay-Coatings on Concrete Performance," J. Mater. Civ. Ing., vol. 22, no. 1, Oct. 2005. http://awards.acpa.org/products/IPRF\%2001-4\%202\%20Clay\%20Dispersion\%20Final\%20Report.pdf

[16] J. C. Restrepo Gutiérrez; O. J. Restrepo Baena; J. I. Tobón, "Efectos de la adición de metacaolín en el cemento Pórtland”, Dyna, vol. 73, no. 150, pp. 131-141, Nov. 2006. http://www.scielo.org.co/pdf/dyna/v73n150/a12v73n150.pdf

[17] Servicio Geológico Mexicano, https://www.sgm.gob.mx/Web/MuseoVirtual/Rocas/Petrografia.html

"Petrografía",

2017.

[18] J. M. Fernández, "Química Analítica Cuantitativa” España: Univ. Navarra, 2013 [En línea]. Available: https://dadun.unav.edu/bitstream/10171/27690/1/Qu\%C3\%ADmica\%20Anal\%C3\%ADtica\%20Cuantitativa . pdf

[19] M. Chambi Tapia; M. Cori Mamani; J. Chungara Castro; S. Fernández Alcázar; O. Ramos Ramos, "Validación del método analítico de fluorescencia de rayos X (FRX-ED) para la determinación de metales en suelos del municipio de Colquencha”, Rev. Boliv. Quim., vol. 36, no. 3, pp. 139-147, Aug. 2019. https://doi.org/10.34098/2078-3949.36.3.4

[20] X. Arroyo Rey, "Difracción de Rayos X (DRX)", [En línea]. Available: https://www.ucm.es/tecnicasgeologicas/difraccion-de-rayos-x-drx 